This PDF is a selection from a published volume from the National Bureau of Economic Research

Volume Title: Means-Tested Transfer Programs in the United States

Volume Author/Editor: Robert A. Moffitt, editor

Volume Publisher: University of Chicago Press

Volume ISBN: 0-226-53356-5

Volume URL: http://www.nber.org/books/moff03-1

Conference Date: May 11-12, 2000

Publication Date: January 2003

Title: Housing Programs for Low-Income Households

Author: Edgar O. Olsen

URL: http://www.nber.org/chapters/c10259 


\section{Housing Programs for Low-Income Households}

Edgar O. Olsen

"Those who do not remember the past are condemned to repeat it"

- George Santayana

\subsection{Introduction}

Unlike other major means-tested transfers, no low-income housing program is an entitlement for any type of household. Despite the failure to serve all eligible households who want to participate, federal, state, and local governments in the United States spend substantially more on housing subsidies to the poor than on other better-known parts of the welfare system such as food stamps and Temporary Assistance for Needy Families (TANF). The most widely cited figures for government expenditures on housing subsidies refer to the direct expenditures of the U.S. Department of Housing and Urban Development (HUD). They ignore the U.S. Department of Agriculture (USDA) programs that account for about 20 percent of all subsidized units, the tax expenditures on the Low-Income Housing Tax Credit ( $\$ 3.5$ billion per year in 2000 and growing rapidly), the expenditures of state and local governments often funded by block grants from the federal government, and the many indirect subsidies such as local property tax exemptions and abatements received by all public housing projects and many privately owned projects, the federal income tax exemption of interest on the bonds issued by state and local governments to finance housing projects, and the underpriced mortgage insurance received by many privately owned projects.

Given the enormous amount of money that has been spent on means-

Edgar O. Olsen is professor of economics at the University of Virginia.

The author is grateful to Neil Seftor for superb research assistance, Robert Olsen and Michael Schill for detailed comments, and Fred Eggers, Dennis Fricke, Bob Gray, Steve Malpezzi, Jim Mikesell, Kathy Nelson, Carla Pedone, Joe Riley, John Quigley, Mark Shroder, Jim Wallace, and John Weicher for helpful conversations. 
tested housing assistance over the years, the amount of research on the most important effects of these programs is shockingly small. There is no evidence on the effects of some major programs and little evidence on the effects of other large programs. For example, there are only two studies of the most important effects of Section 236, a program that still serves almost a million people. There are almost no studies of the important effects of the Low-Income Housing Tax Credit (LIHTC), a program that has been the fastest-growing housing program over the last decade accounting for the majority of additional recipients of housing subsidies. The evidence on the most heavily studied programs is old. For example, the studies of the effects of the public housing program on housing consumption are based on data from 1965 through 1977. At the midpoint of this period, the median age of public housing units was ten years. Today, the median age is about thirty years. It stands to reason that the effect of public housing on the housing consumption of tenants is very different today from what it was at the time of these studies. Since direct HUD expenditure on public housing in the form of operating and modernization subsidies is about $\$ 6$ billion annually and the real resource cost of continuing to use these units to house low-income households is much larger due to their opportunity cost and the substantial local property tax abatement that they receive, this is a sad state of affairs.

If a housing program consists of a set of eligible households and suppliers operating under one set of rules, the United States has had an enormous number of programs intended to improve the housing of low-income households since the federal government became seriously involved in this activity in 1937. There have been many programs as this term is commonly used, each of these programs has typically had a number of variants, and each change in the regulations produces a new program. For example, the public housing program has at least twenty-nine variants. Each has its own rules, and these rules have changed from time to time, although they have many rules in common.

To keep the length of this paper within reasonable limits, it will focus on four broad programs that account for the bulk of all subsidized rental units. These programs are public housing, project-based assistance under the Section 236 and Section 8 New Construction/Substantial Rehabilitation Programs, and tenant-based assistance under the Section 8 Existing Housing Program. They illustrate the three basic approaches that have been used to provide housing assistance: government ownership and operation of housing newly built for occupancy by low-income households; government contracts with private parties to build (or substantially rehabilitate) and operate housing for these households; and subsidies to eligible households who select housing in the private market meeting certain minimum quality standards and, under some variants, other restrictions. These programs account for about 70 percent of all subsidized rental units and about 
50 percent of all units for low-income households that have received federal housing subsidies.

Even though there have been almost no studies of their major effects, a more comprehensive paper would have devoted considerable attention to the LIHTC program (that serves more than a million households and has been growing rapidly since 1988), Section 515 (a rental housing program operated by the USDA in rural areas and small towns that produces few new units each year but still serves more than half a million households), and the HOME housing block grant program from the federal government to state and local housing agencies on which we currently spend about $\$ 1.85$ billion annually, primarily for project-based assistance. In light of the continuing interest in increasing the homeownership rate of the near poor, it would also be desirable to devote considerable attention to several fairly large homeownership programs-HUD's Section 235 program, which provided subsidies to about a half a million households since 1969, and USDA's Section 502 program, which has subsidized almost two million households since 1949 and currently provides subsidies to about half a million households.

The primary purposes of this paper are to (a) consider the arguments that have been offered for housing subsidies to low-income households and the implications of valid arguments for the evaluation and design of housing programs, (b) describe the most important features of the largest rental housing programs for low-income households in the United States, (c) summarize the empirical evidence on the major effects of these programs, and (d) analyze the most important options for reform of the system of housing subsidies to low-income households. The effects of these programs that will be considered include effects on the housing occupied by recipients of the subsidy and their consumption of other goods, effects on labor supply of recipients, the participation rates of different types of households, the distribution of benefits among recipients and all eligible households, effects on the types of neighborhoods in which subsidized households live and the effect of subsidized housing and households on their neighbors, effects on the rents of unsubsidized units, and the costeffectiveness of alternative methods for delivering housing assistance. Since we continue to seriously consider or embark upon new programs that have the same basic features of older programs and the major effects of the newer programs have not been estimated, an understanding of the older programs is highly relevant for current discussions of housing policy.

Section 6.2 discusses the justifications for housing subsidies for lowincome households and goals consistent with these justifications, gives a brief overview of the development of the current system of housing subsidies, and describes in more detail the development and most important rules of the major rental housing programs. Section 6.3 provides information about the number of households served by major programs, direct 
federal expenditures on these programs, and the characteristics of the households assisted. Section 6.4 discusses what can be said on theoretical grounds about the effects of the programs and reviews the evidence on these effects. Section 6.5 analyzes options for reform of the system of housing subsidies to low-income households. Section 6.6 summarizes the major results.

\subsection{Program Justifications, Goals, History, and Rules}

\subsubsection{Justifications and Goals}

Without a clear understanding of the justifications for government activity in a particular area, it is difficult (but not impossible) to conduct an incisive evaluation of current programs or design better programs. For example, a person who has not thought seriously about the justifications for housing subsidies to low-income households might imagine that a housing program for these households is successful if it induces them to occupy better housing. However, a program of cash grants with no strings attached would have this effect for all recipients whose income elasticity of demand for housing is positive - that is, almost everyone. Indeed, it would be possible to devise a subsidy that led to a smaller improvement in housing for all recipients than would result from an equally costly lump-sum grant. A subsidy equal to a fraction of expenditure on all goods except housing would have this effect for recipients whose price elasticity of demand for these other goods is less than one. Should this be considered a successful housing program?

In general, a justification for a government program is an explanation of why we should have a program of that type. Obviously, this involves value judgments. The value judgment underlying this paper is that we should have a program of a particular type if and only if an appropriately designed program of that type will lead to an efficient allocation of resources that is preferred by everyone to the allocation in the absence of government action. Although this simple view leaves much to be desired because it ignores the impact of the multiplicity of external effects, market imperfections, and informational problems that justify other programs and hence the design of a set of programs to deal simultaneously with all of these problems, it is at least a step in the direction of clear thinking about policy evaluation and design.

The major justification for housing subsidies to low-income households is that some taxpayers care about these households but feel that at least some low-income households undervalue housing. If some taxpayers feel this way while others are either completely selfish or nonpaternalistic altruists, it is possible for the government to achieve an efficient allocation and to make everyone better off as they judge their own well-being by pro- 
viding these low-income households with housing subsidies (Olsen 1981). Politicians and lobbyists for housing subsidies rarely use this argument because it is insulting to potential supporters. However, conversations with ordinary citizens about why they prefer to provide housing assistance rather than cash grants usually leads to this argument.

It is clear that paternalistic altruists do not think that all low-income households undervalue housing. In recent years, proponents of housing subsidies have frequently argued that the primary housing problem of lowincome households is an excessive rent-income ratio rather that inadequate housing. That is, the majority of low-income households occupy adequate housing by spending too much of their income on it and hence too little on other goods. People who make this argument must be saying that these low-income households undervalue other goods. If we want to attain an efficient allocation of resources that is preferred by everyone to the allocation in the absence of government action, we must provide nonhousing, rather than housing, subsidies to this group. The implications of these feelings for housing policy are not clear. If housing programs are designed to deal with both poor housing and excessive rent burden, what is the role of food stamps, Medicaid, and other programs designed to subsidize various nonhousing goods?

It is often claimed that housing subsidies to low-income households are justified by more tangible externalities. For example, it has been argued that better housing for low-income families leads to better health for its occupants and, since some diseases are contagious, to better health for the middle- and upper-income families with whom they come in contact. Improvements in the exterior appearance of housing confer benefits on others. Available evidence suggests that some such externalities exist but that their magnitudes are small (Weicher 1979, 489-92). If the goal of housing subsidies is to make both recipients and taxpayers better off, it is doubtful that substantial expenditure can be justified on the basis of these externalities.

Some argue for particular housing programs based on their effects on the members of subsidized households without specifying the nature of the external effect or market imperfection involved and without considering whether the housing program involved is a part of an efficient strategy for dealing with these market failures. For example, many consider a positive effect of a housing program on the educational attainment of children in the subsidized household to be a justification for the program. This argument alone does not justify government action.

No attempt has been made to derive implications for the evaluation and design of government housing programs of a coherent set of justifications for programs of this type. However, the following properties seem broadly consistent with the preceding justifications. First, the program must induce the worst-housed families at each income level to occupy better housing than they would choose if they were given equally costly cash grants with 
no strings attached. This goal is consistent with the stated purposes of the two major housing acts, namely "to remedy the acute shortage of decent, safe, and sanitary dwellings" (Housing Act of 1937) and "the elimination of substandard and other inadequate housing" (Housing Act of 1949). ${ }^{1}$ Second, families that are the same with respect to characteristics of interest to taxpayers should be offered the same assistance. Third, the greatest assistance should go to the neediest families. Finally, the housing provided to participants should have the lowest possible total cost to tenants and governments given its overall desirability.

Other goals for housing programs have been suggested, for example, increasing homeownership, reducing racial segregation in housing, or stabilizing new construction. The rationales for achieving these goals are different from those underlying housing subsidies to low-income families, and they are arguably best achieved by other means.

\subsubsection{History}

Table 6.1 contains some milestones in the development of the system of housing subsidies for low-income households in the United States. ${ }^{2}$ This subsection provides a brief overview of the development of each part of the system, namely public housing, privately owned projects, tenant-based certificates and vouchers, homeownership programs, and housing block grants. The next subsection provides details about the rules governing the four largest rental programs.

\section{Public Housing}

Substantial government involvement in subsidizing the housing of lowincome households began with the Public Housing Program enacted in the U.S. Housing Act of 1937. Public housing projects are owned and operated by local public housing authorities established by local governments. Almost all are newly built for the program. Until 1969, with minor exceptions, federal taxpayers paid the initial development cost of public housing and tenants and local taxpayers paid the operating cost. Between 1968 and 1972 , the federal government greatly increased its previously modest subsidies for operating public housing projects in conjunction with restrictions on the rents that local housing authorities could charge their tenants. In 1969, the federal government began to provide subsidies to local housing authorities for the modernization of their projects. These additional subsidies and restrictions on rent were intended to insure that public hous-

1. In discussions of housing policy, the word "shortage" is not used as economists use it. Instead it means that the market outcome does not provide all households with the type of housing that the speaker thinks they should occupy. All major HUD programs were enacted in these laws or as amendments to them.

2. The dates listed in the table are the dates that programs were enacted. Programs do not become operational until regulations have been written, and this sometimes requires considerable time. 
Table 6.1

Development of System of Housing Programs

\begin{tabular}{ll}
\hline & \multicolumn{1}{c}{ New Programs and Major Modifications of Existing Programs } \\
\hline 1937 & Public housing, HUD, rental, publicly owned \\
1949 & Section 502, USDA, homeownership \\
1954 & Section 221(d)(3) MIR, HUD, rental, privately owned \\
1959 & Section 202, HUD, rental, privately owned, elderly and handicapped \\
1961 & Section 221(d)(3) BMIR, HUD, rental, privately owned \\
1962 & Section 515, USDA, rental, privately owned \\
1965 & Rent supplements, HUD, rental, extra subsidy to private projects \\
1965 & Section 23, HUD, rental, leasing existing units for public housing tenants \\
1968 & Section 235, HUD, homeownership \\
1968 & Section 236, HUD, rental, privately owned \\
1969 & Modernization subsidies for public housing \\
1969 & Rents in public housing limited to 25 percent of income \\
1970 & Substantial operating subsidies for public housing \\
1974 & Section 8 Existing, HUD, rental, tenant-based \\
1974 & Section 8 New Construction/Substantial Rehabilitation, HUD, rental, privately \\
& owned \\
1975 & Operating subsidies for public housing (Performance Funding System) \\
1976 & Operating subsidies for privately-owned projects (LMSA and PD) \\
1979 & Modernization subsidies for privately owned projects (Flexible Subsidy) \\
1983 & Housing Voucher Demonstration, HUD, rental, tenant-based \\
1986 & LIHTC, IRS, rental, privately owned \\
1990 & HOME, HUD, rental and homeownership, block grants to states and localities \\
1998 & Housing Choice Voucher Program, HUD, rental, tenant-based \\
\hline
\end{tabular}

ing would provide satisfactory housing to its tenants without charging rents that were regarded as excessive.

\section{Privately Owned Projects}

In 1954, the federal government began to contract with private parties to provide housing for low-income households. Under most programs, these parties agreed to provide housing meeting certain standards to households with particular characteristics for a specified number of years. The overwhelming majority of the projects were newly built. Almost all of the rest were substantially rehabilitated as a condition for participation in the program. The federal government insures the mortgages on the vast majority of these projects, and default loss in excess of mortgage insurance payments is a major indirect cost of many of the programs. It is important to realize that none of these programs provide subsidies to all suppliers who would like to participate. Since subsidies are provided to selected private suppliers, the market mechanism does not insure that subsidies are passed along to occupants of the subsidized units. In all cases, civil servants are involved in ranking proposals. In most programs, political appointees make the final decisions.

The earlier programs such as HUD's Section 221(d)(3) Market Interest Rate Program and Section 202 limited the private parties who operate the 
projects to nonprofits and cooperatives. ${ }^{3}$ They were succeeded by programs that allowed the participation of for-profit firms, while attempting to limit their profits by restricting their net revenues during the period of the use agreement. For-profit firms have accounted for the majority of the units in the most recent programs such as Section 8 New Construction/ Substantial Rehabilitation and the LIHTC. Despite this trend, nonprofits still account for a substantial minority of units under some recent programs such as the LIHTC. ${ }^{4}$

The earlier programs (Section 221[d][3] MIR and Section 202) did not have income limits. Instead they attempted to insure occupancy by households of low and moderate income by limiting the per-unit cost of the project, thereby providing relatively modest housing. The subsidy under the earlier programs was a below-market interest rate on the loan used to finance the project, and the subsidy received by an occupant of the project did not depend on the household's income. The modest magnitude of the subsidy and the high cost of newly built housing meeting the program's standards resulted in few units occupied by the poorest households.

The initial response to this situation (HUD's Section 221[d][3] BMIR Program) was to provide a larger interest subsidy, thereby reducing the rent to tenants at all income levels by the same amount. Another response (for example, the Rent Supplement Program) was to provide an additional subsidy to many of the poorest households in projects that received an interest subsidy in order to reduce their rents to 25 percent of their adjusted incomes. (The poorest of the poor paid a flat rent equal to 30 percent of the rent that would otherwise be charged for the apartment.) Rent supplements were used almost exclusively with the Section 221(d)(3) MIR and the Section 236 programs.

The basic HUD Section 236 program and the USDA's 515 program are similar to the Section 221(d)(3) BMIR program in providing a substantial interest subsidy that reduces the rent of all of the poorest households occupying identical apartments in a project by the same amount. The more affluent among the eligibles initially paid 25 percent of their adjusted incomes. Over time, an increasing fraction of the poorest occupants of these projects have received additional subsidies under a succession of programs that initially reduced their rents to 25 percent of adjusted income and later to 30 percent. ${ }^{5}$ Some of these programs were intended to insure that proj-

3. The original Section 221(d)(3) program is usually called the Market Interest Rate Program (MIR). This is misleading because the program does provide financing at below-market interest rates, albeit not as far below market as the later Section 221(d)(3) Below-Market Interest Rate (BMIR) Program.

4. The extent of the involvement of the two types of sponsor is not well documented because they often work in partnership and only one is listed as the sponsor in official records.

5. The programs involved were the Rent Supplement Program, the Rental Assistance Payments Program, Section 8 Conversion Assistance, and the Section 8 Loan Management SetAside (LMSA) and Property Disposition (PD) Programs. 
ects built under construction programs continued to house low-income households and to avoid defaults on loans insured by the federal government. However, about a fourth of the occupants of apartments in privately owned HUD-subsidized projects have rents that do not vary with their income (HUD 1997, 3).

In 1978, Congress enacted the Flexible Subsidy Program to provide modernization subsidies to older privately owned subsidized projects, especially under Section 236, 221(d)(3), and 202, just as it had done earlier for public housing. The money is awarded on a competitive basis rather than by formula.

The largest program of subsidized privately owned projects for lowincome households is HUD's Section 8 New Construction/Substantial Rehabilitation Program, enacted in 1974. Section 8 New Construction/Substantial Rehabilitation provides not only subsidies for the construction or rehabilitation of projects but also rental assistance payments that initially reduced the rents paid by all tenants to 25 percent of their adjusted incomes. ${ }^{6}$

With minor exceptions, Congress had terminated all of HUD's construction programs by 1983. Section 236 replaced Section 221(d)(3) BMIR, Section 8 New Construction/Substantial Rehabilitation replaced Section 236, and Section 8 New Construction/Substantial Rehabilitation was terminated in 1983 in the sense that no additional applications for projects under this program were accepted after this time. ${ }^{7}$ This was in response to the large per-unit cost under all new construction programs compared with tenant-based Section 8 Certificates and studies indicating that these costs were also large relative to the market rents of the units provided. Only public housing and the small Section 202 program for the elderly and handicapped, which had been revised to operate like the Section $8 \mathrm{New}$ Construction/Substantial Rehabilitation Program, were allowed to approve a modest number of additional applications.

The LIHTC was enacted hastily as a part of the Tax Reform Act of 1986 to replace other tax subsidies for low-income housing that were eliminated. ${ }^{8}$ Within a few years, it will become the second largest program of

6. Beginning on 1 August 1982, it increased periodically until it reached 30 on 1 October 1985.

7. It is a testimony to the long lags between the appropriation of money under construction programs and their completion that the number of occupied units under this program continued to grow for thirteen years after its termination. For systematic evidence on these lags, see Schnare et al. (1982, table 4-8).

8. Virtually nothing is known about the effects of the LIHTC. There is no repository of information on the characteristics of the households served by this program or the characteristics of the housing provided. Some rudimentary statistical information can be found at http:/ /www.huduser.org/datasets/lihtc.html. What is known about the program is the result of a few studies. Wallace $(1995,794-801)$ provides an accurate description of the program's rules and a summary of basic descriptive statistics that had been produced by earlier studies. Cummings and DiPasquale (1999) add an unusually thorough analysis of all of the subsidies pro- 
housing subsidies to low-income households, surpassing public housing. For projects not financed by tax-exempt bonds, the tax credit pays 70 percent of the cost of developing the project. The tax credit is not available to all developers who want to build housing under the terms specified in the law. Instead each state housing finance agency is allocated an amount of money that is proportional to the state's population to distribute to selected private suppliers. In recent years, developers have proposed projects that would use three times the amount of money appropriated for the program, and many do not apply because the probability of success is too small to justify the effort.

The overwhelming majority of tax credit projects receive subsidies from other sources, primarily development grants or loans at below-market interest rates from state and local governments and rental assistance payments that depend upon the income of the tenants. These additional development subsidies account for about a third of the total capital subsidy (Cummings and DiPasquale 1999, table 7), and owners of tax credit properties receive rental assistance payments on behalf of about 39 percent of their tenants (GAO 1997, 40). The typical project receives subsidized financing from many sources, thereby complicating the task of insuring that the subsidy is passed along to the tenant. The median was five in Stegman's nonrandom sample of twenty-four projects (Stegman 1991, 362).

Under the LIHTC, the tenant's maximum rent is 30 percent of the upper income limit for eligibility. ${ }^{9}$ Tenant rent within a project does not vary with income except for households who receive assistance from other programs that require it. As a result, the poorest households occupy relatively few LIHTC units. According to Wallace $(1995,790)$, only 28 percent of households in LIHTC projects are very low-income as HUD defines this term (50 percent of local median for a family of four). The percentages are 90 for Section 8 New Construction, 81 for public housing, and 77 for Section 236 and 221(d)(3) BMIR.

\section{Tenant-Based Assistance}

Until 1965, all housing assistance to the poor was project based and the overwhelming majority of units were newly constructed under a govern-

vided for the development of LIHTC projects. This analysis does not, however, include the substantial tenant-based and project-based Section 8 subsidies received by about 39 percent of the units (GAO 1997, 40). GAO (1997) and Buron et al. (2000) provide additional descriptive material. Despite the absence of evidence on the effects of the LIHTC, Congress in 200001 increased tax expenditure for this program by more than 40 percent to about $\$ 5$ billion per year and indexed appropriations to inflation. Shortly thereafter, GAO (2002) produced the first independent analysis of the cost-effectiveness of the program.

9. The upper income limit for a family of four is effectively 60 percent of the local median. Increasing or decreasing these income limits by nationally uniform percentages used for the largest HUD programs yields the income limits for households of other sizes. 
ment program. In 1965 Congress created Section 23, a program under which public housing authorities could lease apartments in existing private unsubsidized housing for the use of households eligible for public housing. ${ }^{10}$ One variant of this program allowed tenants to locate their own apartments meeting the program's minimum standards. This was the first program of tenant-based assistance in the United States. In 1974, the Section 8 Existing Housing Program replaced Section 23. Since then, tenantbased Section 8 has become the country's largest program of housing assistance. This program was called the Certificate Program. Another program of tenant-based housing assistance, called the Section 8 Voucher Program, that had somewhat different constraints than the Certificate Program was introduced in 1983. This program operated simultaneously with the Certificate Program until 1998, when the two programs were consolidated into another tenant-based program that combined features of the two earlier programs.

Despite the rapid growth of the tenant-based Section 8 Certificate and Voucher programs, the majority of additional recipients of rental housing assistance since 1975 have received project-based assistance. Between 1975 and 1990, the major sources of this assistance were Section 8 New Construction/Substantial Rehabilitation and Section 515. Since 1990, the overwhelming majority of HUD's incremental assistance has been tenant based, but project-based assistance has continued to account for the majority of additions to number of subsidized households in the United States due to the rapid growth of the Internal Revenue Service's LIHTC. Furthermore, HUD spends a substantial fraction of its budget providing additional assistance to units in subsidized housing projects beyond the subsidies initially promised.

\section{Homeownership Programs}

The United States has had two major homeownership programs that provide housing assistance to low-income households. The Housing Act of 1949 established the USDA's Section 502 Single Family Direct Loan Program. ${ }^{11}$ Until 1968, the magnitude of the subsidy was modest and did not depend on the household's income. The subsidy consisted of lending at the federal borrowing rate to farmers and others living in rural areas. (Farmers now account for a small share of all borrowers.) The Housing Act of 1968 authorized the USDA to pay a portion of the loan repayments for low-income households. For the poorest households, the USDA paid the

10. For a comprehensive analysis of this program and a detailed survey of the literature on it, see Reid (1989).

11. See Carliner $(1998,314-15)$ for a brief history of the development of the program and Mikesell et al. (1999) for descriptive statistics and the first analysis of this program based on a nationally representative survey. 
difference between principal and interest payments at the government's borrowing rate and at an interest rate of 1 percent. For eligible households with higher incomes, the USDA paid the difference between property taxes, homeowners insurance, operating expenses, and principal and interest payments at the government's borrowing rate and 20 percent of the household's adjusted income. During its fifty-year history, the Section 502 Single Family Direct Loan Program has provided over $\$ 51$ billion in homeownership loans to about 1.9 million households. The program currently provides subsidies to over 500,000 low-income households.

The Housing Act of 1968 established Section 235, a HUD program similar in many respects to USDA's Section 502. Unlike Section 502, this program suffered from scandals and high default rates (Carliner 1998, 31314). Section 235 was suspended in 1973, reactivated in 1975, severely limited in geographical scope in 1983, and terminated in 1987. Over this period, it provided subsidies to more 500,000 low-income households. Little is known about the reasons for the difference in outcomes of the two programs. The poor performance of Section 235 is usually attributed to consumer naivete and Federal Housing Administration (FHA) mismanagement. More plausible explanations would rely on differences in the structures of the programs such as the magnitude of the down payment required and whether the subsidy is allocated to the seller or the buyer of the house.

\section{Housing Block Grants}

The HOME Investment Partnerships Program enacted in 1990 is a block grant for housing assistance. It allocates federal funds by formula to state and local governments to spend on any type of housing assistance subject to certain limits on the incomes of the households served, the cost to acquire and develop units, and the rents that may be charged for rental units. This program is based on the untested assumptions that the best mix of housing programs differs from locality to locality and local officials are better able to determine and implement the best mix. ${ }^{12}$

\subsubsection{Rules}

This section presents information concerning many of the important rules governing HUD's four largest programs of rental housing assistance for low-income households and the evolution of these rules over the history of the programs. The rules considered determine who is eligible to receive assistance, how the limited assistance is allocated among households that would like to participate, upper and lower limits on the desirability of the

12. These assumptions could be tested by comparing the outcomes of different federal programs across localities to see whether one program performs better than all others on all measures and then comparing the overall effect of the mix of programs chosen by local officials with the federal mix in a random sample of localities. 
housing that can be occupied, and upper limits on spending on goods other than housing. These rules affect which households are served and a program's effects on consumption patterns.

Other rules that determine the incentives facing potential and actual suppliers will not be discussed. For construction and rehabilitation programs, these rules affect the types of housing that will be proposed and selected. For all programs, they affect how well the units will be maintained and the total cost of the housing provided. Although these rules determine the cost-effectiveness of a program and the level of housing services provided, they have not been seriously analyzed by housing policy analysts. This represents a major gap in our knowledge of housing programs.

It is not possible within reasonable time and space constraints to describe accurately the rules of the four programs that are the focus of this paper over their histories. The rule describing what is and is not included in a household's annual income in determining its eligibility for assistance illustrates the problem. The current rule is more than three pages single spaced. This rule is now the same for all major low-income housing programs. In earlier years, it was different for different programs, and it has been changed on a number of occasions over the history of each program.

Researchers who want to conduct empirical studies of the effects of housing programs, or indeed any program, should consult the Code of Federal Regulations (CFR) for the time period to which their data refer to determine the rules that were in effect at that time. ${ }^{13}$ The regulations for HUD are in Title 24 of the CFR. That is, references to them all begin with 24CFR. For example, since 1996 the reference for HUD's physical condition standards for virtually all subsidized housing has been 24CFR5.703. In earlier years, the standards for each program were located in the CFR under the regulations for that program.

The CFR is an annual publication that contains the updated regulations of the federal government as of April 1. A searchable electronic version containing the CFR and the Federal Register since 1981 is available at $\mathrm{http}: / /$ web.lexis-nexis.com/congcomp/. Virtually all rules of interest must be published in the Federal Register along with the date on which they became effective, and each regulation in the CFR cites the relevant passage

13. In the case of housing programs, secondary sources, even government publications or agency websites, are always incomplete and sometimes erroneous. For example, it is often said in official HUD documents that the upper income limit for admission to public housing is 80 percent of the local median. This might lead the unsuspecting to conclude that the income limit is the same for families of all sizes, or perhaps that for families of each size it is 80 percent of the local median for families of that size. Neither is correct. Reading the legislation is not a substitute for reading the regulations. Legislation typically specifies some, but not all, of a program's rules. It provides general guidelines concerning other matters, but leaves the design of specific regulations to the administering agency. Furthermore, the operation of a program does not change with the passage of legislation. This does not occur until after new regulations have been announced in the Federal Register. 
in the Federal Register. For example, the citation for the proposed regulation that ultimately led to a unified set of physical condition standards applying to all low-income housing programs is 63FR35650. As usual, this source contained a history of previous regulations. The citation for the final rule is 63FR46566, which contains the date on which the regulation became effective.

These sources are useful not only for researchers who have a data set that identifies which households participate in housing programs and are attempting to determine the parameters of the budget spaces of these households but also to others who are trying to learn when major changes in program parameters occurred with an eye to selecting which data to use to maximize exogenous variation in budget constraint parameters. Using these sources, it is easy to determine when important changes in the regulations have occurred.

Prior to the regulations implementing the Housing and Community Development Act of 1974, there was considerable diversity in the rules of different housing programs. This legislation introduced many similarities in the rules across programs, and this trend has continued over the past twenty-five years, culminating in the 1990s with the placement of many common rules in Part 5 of Title 24 of the CFR. These include rules for preferences for admission into subsidized housing (24CFR5.4XY since 1996), income limits, the definitions of annual income and adjusted income, tenant rents, and certifying eligibility (24CFR5.6XY since 1997), and minimum physical housing standards (24CFR5.7XY since 1999).

To help aspiring housing policy analysts navigate through the regulations and to provide others with an overview of the rules that have governed low-income housing programs, this section describes the key rules that prevailed on 1 April 1999 and some of the major changes that have occurred in these rules over the years.

Before proceeding, it is useful to mention several general features of the rules. In recent years, the majority of privately owned projects under HUD's programs receive project-based Section 8 housing assistance payments and are therefore subject to the key rules of the Section 8 program. Since the enactment of the Section 8 program in 1974, Section 8 and public housing have had very similar rules in many respects. This means that the overwhelming majority of HUD's subsidized households are subject to many of the same rules.

\section{Eligibility}

With a few minor exceptions such as Section 221(d)(3) MIR and Section 202 in its early years, all housing programs have had upper income limits for eligibility. Indeed, the earlier programs such as public housing had two limits for households of each size—one for initial receipt of a subsidy and 
a larger limit for retaining the subsidy. ${ }^{14}$ The income limits that are discussed here and elsewhere are limits for initial receipt of a subsidy unless otherwise stated.

Prior to the 1974 Housing Act, local public housing authorities chose their own upper income limits based on a vaguely worded provision of the law. The upper income limits for other programs were related to the limits for public housing and always greater than these limits. For example, the income limits for Section 236 in its early years were 35 percent above the limits for public housing in the same locality.

Since the 1974 Housing Act, public housing, Section 236, and all variants of Section 8 have had a common set of income limits. These programs account for the overwhelming majority of HUD-subsidized households. Each year, the Economic and Market Analysis Division (EMAD) in HUD's Office of Policy Development and Research estimates these limits in accordance with the regulations.

The basic income limit for a family of four is 80 percent of the median income of all families in a locality. ${ }^{15}$ Income limits for families of other sizes are obtained from the four-person income limit by applying the following percentages. $^{16}$

Family Size and Percentage Adjustments

\begin{tabular}{lccccccc}
\hline 1 & 2 & 3 & 4 & 5 & 6 & 7 & 8 \\
$70 \%$ & $80 \%$ & $90 \%$ & $100 \%$ & $108 \%$ & $116 \%$ & $124 \%$ & $132 \%$
\end{tabular}

In the terminology of housing regulations and policy discussions, these families are described as low-income families. ${ }^{17}$ In the absence of excep-

14. The earliest housing programs involved construction and so households had to move in order to receive the subsidy. Even after these programs stopped producing additional units, households entering the program had to move into a project in order to receive a subsidy. The higher limit for continued occupancy was introduced to avoid forcing a household to move if its income rose too much. This problem only arises if the market rent of the unit occupied exceeds the tenant's rent at the upper income limit for admission, that is, if there is a notch at this upper income limit. This is almost surely the case for every construction program in its early years when the housing is new. Based on a vague provision in the law, many local housing authorities set their upper income limits for continued occupancy 25 percent above their limits for admission. Public housing has not had a separate upper income limit for continued occupancy for many years. If a public housing tenant's income rises above the income limit for admission, the housing authority could force the tenant to leave the project, but this rarely happens. Under Section 8 certificates and vouchers, the effective upper income limit for continued receipt of a subsidy is the income at which the subsidy is zero.

15. Income limits were related to local median incomes in an attempt to account for geographical price differences, but differences in median incomes obviously also reflect other factors such as differences in skill levels.

16. There is no good rationale for these percentages. For example, they are not based on differences in poverty lines for households of different sizes.

17. To put these limits in perspective, the poverty line is about 30 percent of median income. 
tions, only low-income families are eligible for the housing programs that account for almost all means-tested housing subsidies.

However, there are important exceptions to these simple rules. In 2000, these affected the limits for 37 percent of the metropolitan areas and 86 percent of the non-metropolitan areas. The most important exception in terms of the number of areas affected is the requirement that the income limits in a nonmetropolitan area may not be less than limits based on the state nonmetropolitan median family income.

In a series of amendments to housing laws since 1975, Congress has specified that an increasing percentage of recipients of housing subsidies have incomes below 50 percent of the local median for four-person families and the aforementioned adjustments for family size. ${ }^{18}$ These households are called very low-income households, and these laws are codified in 24CFR1275 (1975), 24CFR882 (1976), 24CFR813 (1985), and 24CFR982 (1999).

Finally, the Quality Housing and Work Responsibility Act of 1998 created a new category called extremely low-income families, whose incomes were 30 percent of the local median for families of four and required a high percentage of new recipients of housing subsidies to be in this category (24CFR982.201 [2000]). Consistent with a trend over several decades to avoid concentrations of the poorest households in public housing, the required percentage was much lower for public housing than tenant-based vouchers and certificates. Specifically, the act required that at least 75 percent of new recipients of tenant-based vouchers and only 40 percent of new recipients of HUD's project-based assistance have extremely low incomes.

The details concerning the rules and methods for calculating income limits are contained in fiscal year (FY) 2000 Income Limits Briefing Material available at http://www.huduser.org/datasets/il.html. Fortunately, understanding these complexities is not important for most purposes because the income limits themselves are available in electronic form for all areas from 1990 to the present at the aforementioned website. They can be obtained for earlier years through HUD's Economic Market Analysis Division (EMAD).

Unlike many other means-tested welfare programs, there are no asset tests for eligibility for housing assistance. Actual or imputed income from specified assets is included in income in determining eligibility and rent.

18. The income limits calculated based on 80 percent of the local median and income limits for virtually all other housing programs, including non-HUD programs, that use different percentages are calculated by first calculating the limits based on 50 percent, then applying the exceptions, and finally multiplying by the relevant percentage. For example, almost all LIHTC projects involve a program option that restricts the rents of tenants to income limits based on 60 percent of the local median. To calculate these limits, the limits based on 50 percent are multiplied by 1.2 . 


\section{Preferences}

Since housing programs are not entitlements, some system is required to allocate the available money to the many families that would like to participate. ${ }^{19}$ The most salient feature of the system is that there has never been a uniform national system to rank families on a waiting list. Instead Congress has specified that some preference must be given to certain types of families but left it to local housing authorities and owners of subsidized private projects to devise preference schemes. For example, in 1971 Section 10(g)(2) of the United States Housing Act of 1937 read as follows:

The public housing agency shall adopt and promulgate regulations establishing admissions policies which shall give full consideration to its responsibility for the rehousing of displaced families, to the applicant's status as a serviceman or veteran or relationship to a serviceman or veteran . . . , and to the applicant's age or disability, housing conditions, urgency of housing need, and source of income: Provided, That in establishing such admission policies the public housing agency shall accord to families of low income such priority over single persons as it determines to be necessary to avoid undue hardship.

HUD has never been authorized to establish a nationally uniform preference system. Its role has been to review preference systems for consistency with congressional intent.

Obviously, there are infinitely many schemes for ranking families on a waiting list that give some preference to the types of households mentioned in this passage. There are now about 3,400 local public housing authorities and more than 22,000 privately owned HUD-subsidized projects. Although some undoubtedly copy the schemes of others, it seems likely that there have always been an enormous number of different schemes in existence. A common scheme has been to assign points to different family attributes mentioned in the law. However, there are infinitely many different weights that could be assigned to the favored household types consistent with the wording of the law. ${ }^{20}$

Although the language of the law with respect to priorities for receipt of housing subsidies has changed from time to time and other types of families have been singled out for preferential treatment, some of the family types mentioned in the preceding passage have been accorded preferential

19. The next section discusses the extent of the excess demand for assistance to the extent possible with existing data.

20. This creates a problem for research where information on the preference scheme is important. These preference systems could be collected because each public housing agency and manager of a privately owned project is required by law to have a written preference scheme that is available to the public. However, it would be quite expensive to do it for all subsidized housing because they are not available in HUD's central office. 
treatment for receipt of housing assistance under many programs over much of their histories. The elderly and handicapped have been given a preference for subsidized housing for at least forty years. There are two programs (Section 202 and 811) limited to such households, many projects built under other programs are built exclusively for them, and they have typically been given priority for admission into projects not built exclusively for them. Families living in substandard housing or displaced by government action have always been given a preference for housing subsidies. ${ }^{21}$ Single persons who are not elderly, disabled, or displaced by government action have always been given a low priority for assistance.

Congress suspended federal preferences on 26 January 1996 and repealed them in the Quality Housing and Work Responsibility Act of 1998 (64FR23460, 65FR16692). The final regulations implementing these changes became effective 30 April 2000. Since these legislative changes did not require housing authorities to alter their current preference system, it is likely that they had little immediate effect. Immediately prior to the suspension of federal preferences, federal law required that for the overwhelming majority of new recipients of housing assistance, local housing authorities must give preference to families who were occupying substandard housing, involuntarily displaced, or paying more than 50 percent of income for rent. They were allowed to use local preferences for a small minority of new recipients (53FR1122).

\section{Restrictions on Housing Consumption}

Under all forms of project-based housing assistance, households that reach the top of the waiting list are offered a particular unit. To a first approximation, they have no choice concerning the quantity of housing services that they consume if they want to receive housing assistance. It is only to the extent that they can reject particular units without dropping to the bottom of the waiting list and the possibility of being simultaneously on the waiting lists for public housing and individual private projects that eligible families have a range of housing choices. ${ }^{22}$ Even if we ignore the complexities resulting from these possibilities, it is not the case that all households offered assistance under a project-based program are offered the same housing. Under mature construction and substantial rehabilitation programs, the variance in the desirability of the program's units of a particular size is enormous. Therefore, the housing offered by these programs at a point in time cannot be characterized by a single number such as its

21. Many involved in discussions of housing policy view living in substandard housing as something that happens to a person rather than something that is chosen.

22. Some housing authorities allow tenants to reject a few units before being dropped from the waiting list. Nothing prevents eligible households from being on the public housing waiting list and simultaneously applying for an apartment in any privately owned subsidized project. 
market rent divided by a housing price index or a single vector of characteristics. As explained later and depicted in figure 6.4, families eligible for tenant-based housing vouchers or certificates have a wide range of housing choices, but the program adds the same consumption bundles to the budget spaces of all eligible families with the same characteristics living in one locality provided that they are offered assistance.

Since a primary goal of housing programs is to improve the housing occupied by participants, it should not be surprising that almost all housing programs have minimum housing standards. For some programs such as the older programs involving privately owned projects, these standards have been so vague as to be unenforceable. They require that the housing be decent, safe, and sanitary. For others such as tenant-based vouchers and certificates, much more specific standards have existed. ${ }^{23}$ It was not until 1999 that the same detailed standards applied to virtually all subsidized housing (63FR46566).

With the exception of the housing voucher program that began as a demonstration in 1983 and is currently being phased out, all housing programs place upper limits on the quantity of housing available to participants. In the case of production programs, these result from upper limits on construction costs and limits on the amount of money that the housing authority or owner of a private project can receive from the tenant and the government each month. Although this limits how good any program unit can be, it is not a parameter of the budget space of most households offered units under the program. Due to depreciation, units under mature production programs differ widely in their condition. A household's budget space depends on which unit it is offered. With the exception of the aforementioned voucher program, the other programs of tenant-based assistance impose upper limits on the rents that landlords can receive. This upper limit is a parameter of the budget space of each household offered assistance under a particular program in a specific locality.

Under all housing programs, the size of the apartment offered to a household depends on the size and composition of the household. For example, two children of the same sex will be expected to share a bedroom. Beyond a certain age, two children of different sexes will have their own bedrooms.

\section{Tenant Rent}

For more than thirty years, the tenant's contribution to rent under all construction programs has been specified in the program's regulations. For all units in the largest programs (public housing and Section 8 New Construction/Substantial Rehabilitation) and many units in other programs, it has depended on household characteristics, but not on the desirability of the housing occupied. Similar remarks apply to the Section 8 Certificate 


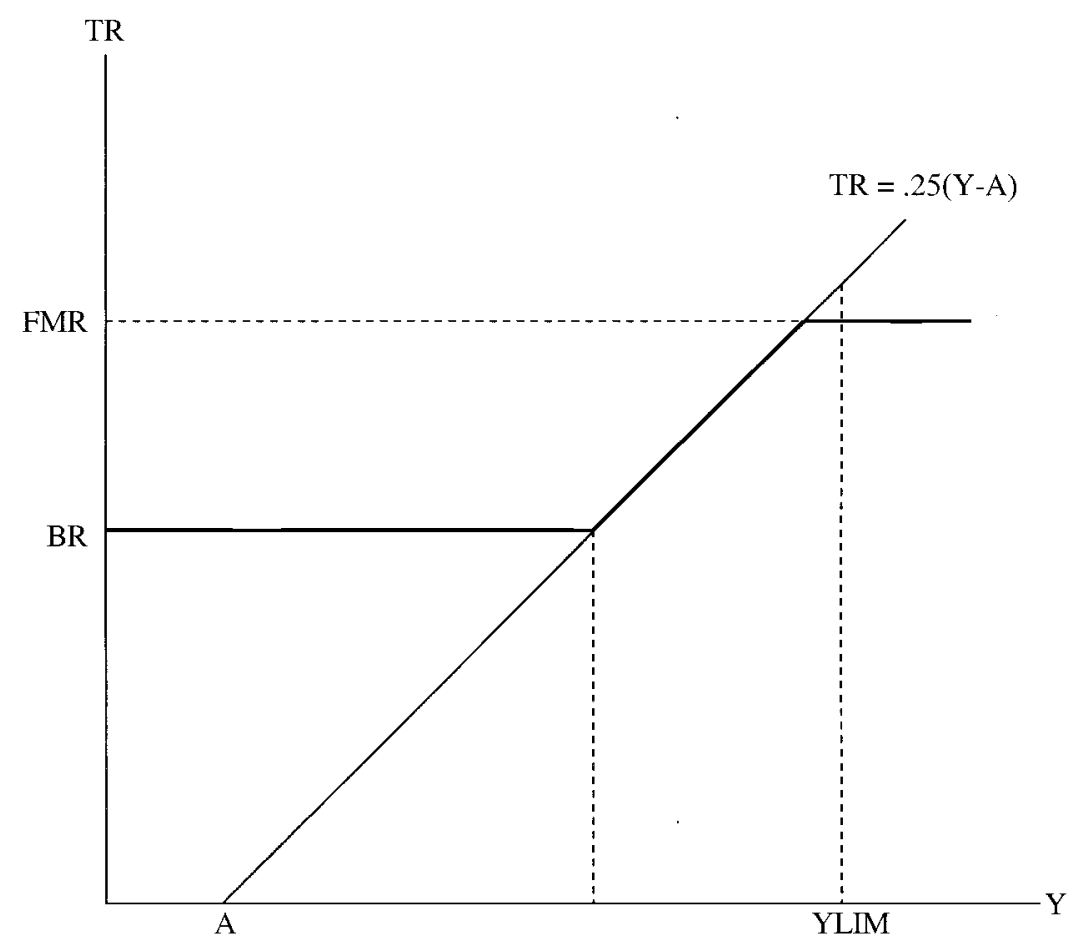

Fig. 6.1 Tenant rent under section 236 without rent supplements

Program since 1980. For the other programs of tenant-based assistance, the tenant's contribution to rent depends on the market rent of the apartment selected.

In public housing prior to 1969 , each local housing authority had its own system for determining the rent paid by public housing tenants subject to very general guidelines. Some housing authorities charged a fixed fraction of adjusted income (usually 20 percent), others charged the same rents for all apartments of the same size, and still others charged a certain minimum rent to the poorest households and a fraction of adjusted income to households for which this was larger. In 1969, legislation imposed a uniform upper limit on rents at 25 percent of adjusted income, and almost all local authorities charged the maximum rents permitted. Between 1982 and 1985, a transition to a higher percentage - 30 percent - occurred, and the authorities were required to charge this rent. The Section 8 New Construction/Substantial Rehabilitation Program and the Section 8 Certificate Program after 1980 used the 25 percent rule initially and made the aforementioned transition to 30 percent in the early 1980s.

The history of the rules for tenant rent in the Section 236 program is similar to the history in several other construction programs. The thick lines in figure 6.1 depict how the tenant's rent TR under Section 236 without rent 


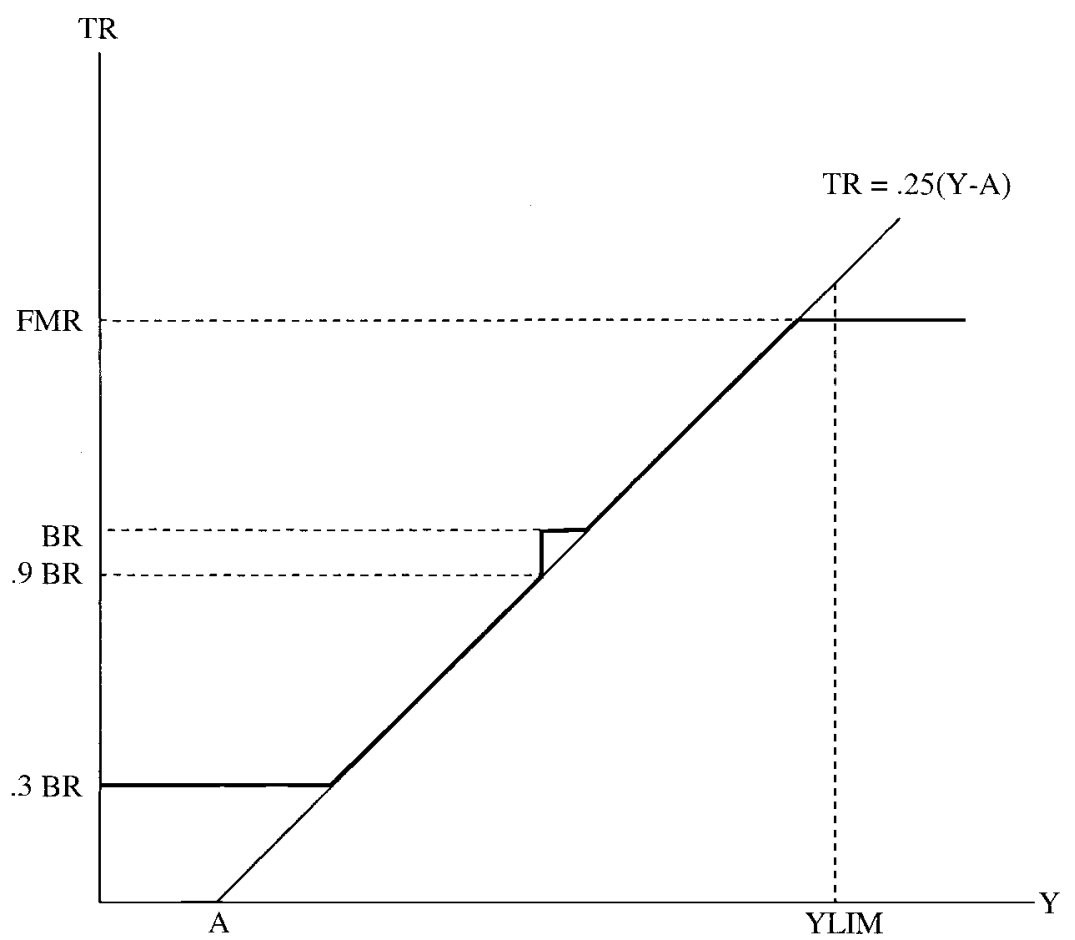

Fig. 6.2 Tenant rent under section 236 with rent supplements

supplements or other additional subsidies varies with the tenant's income $Y$. In the diagrams, FMR is the sum of the allowed monthly costs of providing an apartment, including repayment of the mortgage loan at the interest rate charged by the lender. ${ }^{24}$ HUD directly pays enough of the mortgage payment to reduce the effective interest rate to one percent. This determines the basic rent BR paid by the poorest participants. Richer participants paid 25 percent of their adjusted incomes, and owners rebated to HUD the excess of this amount over BR. If the upper income limit for eligibility YLIM is sufficiently high that 25 percent of the adjusted incomes of some tenants exceeds FMR (as in figure 6.1), their rent is FMR.

The thick lines in figure 6.2 depict how the tenant's rent varies with income for Section 236 with rent supplements. The Rent Supplement Program was an attempt to make it more attractive for the poorest households to occupy units in these projects and for the owners of the projects to accept these tenants by guaranteeing a part of the rent payment. ${ }^{25}$ To achieve

24. This interest rate is below the market rate due to indirect interest subsidies. For this and other reasons, FMR should not be interpreted as the market rent of the unit.

25. The Rent Supplement Program enacted in 1965 was always used in conjunction with subsidized construction programs involving private ownership of housing projects, especially Section 236 and Section 221(d)(3) MIR. Piggybacks with other construction programs were 
this goal, the program paid a portion of the rent that the poorest households would otherwise have to pay to live in these projects. Specifically, these extra payments reduced tenant rents to 25 percent of adjusted income except when this was less than $0.3 \cdot \mathrm{BR}$. In that event, the tenant paid $0.3 \cdot \mathrm{BR}$. The minimum rent supplement payment was $0.1 \cdot \mathrm{BR}$. A succession of later programs replaced the Rent Supplement Program in providing additional subsidies to the poorest households in privately owned subsidized projects.

\subsection{Program Statistics}

Table 6.2 contains the standard information on the number of households assisted by each broad type of housing program. In some respects, these numbers are misleading.

First, the numbers concerning assisted homeowners are not comparable to the numbers for rental assistance. When the loan on a unit subsidized under a means-tested homeownership program is repaid that household is no longer counted as being assisted even though it continues to live in the house. That is one reason why the number of homeowners assisted has declined. This contrasts sharply with rental assistance where households living in housing built under new construction programs are counted independent of whether the mortgage has been repaid as long as these households continue to receive a subsidy. In fact, the purchase of more than 2.5 million houses has been subsidized under Section 235, Section 502, and other smaller programs.

Second, the numbers in table 6.2 reflect only households assisted by HUD and USDA. They take no account of the large number of households assisted by the LIHTC. About 700,000 households lived in such units in 1998 (table 6.5). Further, these numbers do not account for households that receive subsidies from only state and local programs.

With these caveats in mind, we see that in percentage terms the fastestgrowing part of the system of rental housing subsidies over this period has been household-based assistance to live in existing units. Recall, however, that there were no programs in this category prior to 1965 when the small precursor to the Section 8 Existing Housing Program was established. In total, more additional households have been served over the past twenty years by new construction programs than by household-based certificates and vouchers even when the LIHTC is ignored.

Table 6.3 contains the standard numbers on HUD outlays. It shows that, contrary to newspaper accounts, real expenditure on housing assistance

rare. Except for providing supplements for projects in the pipeline at the time, no new commitments under this program have been made since 5 January 1973. At its peak, the program provided subsidies to about 180,000 households. 


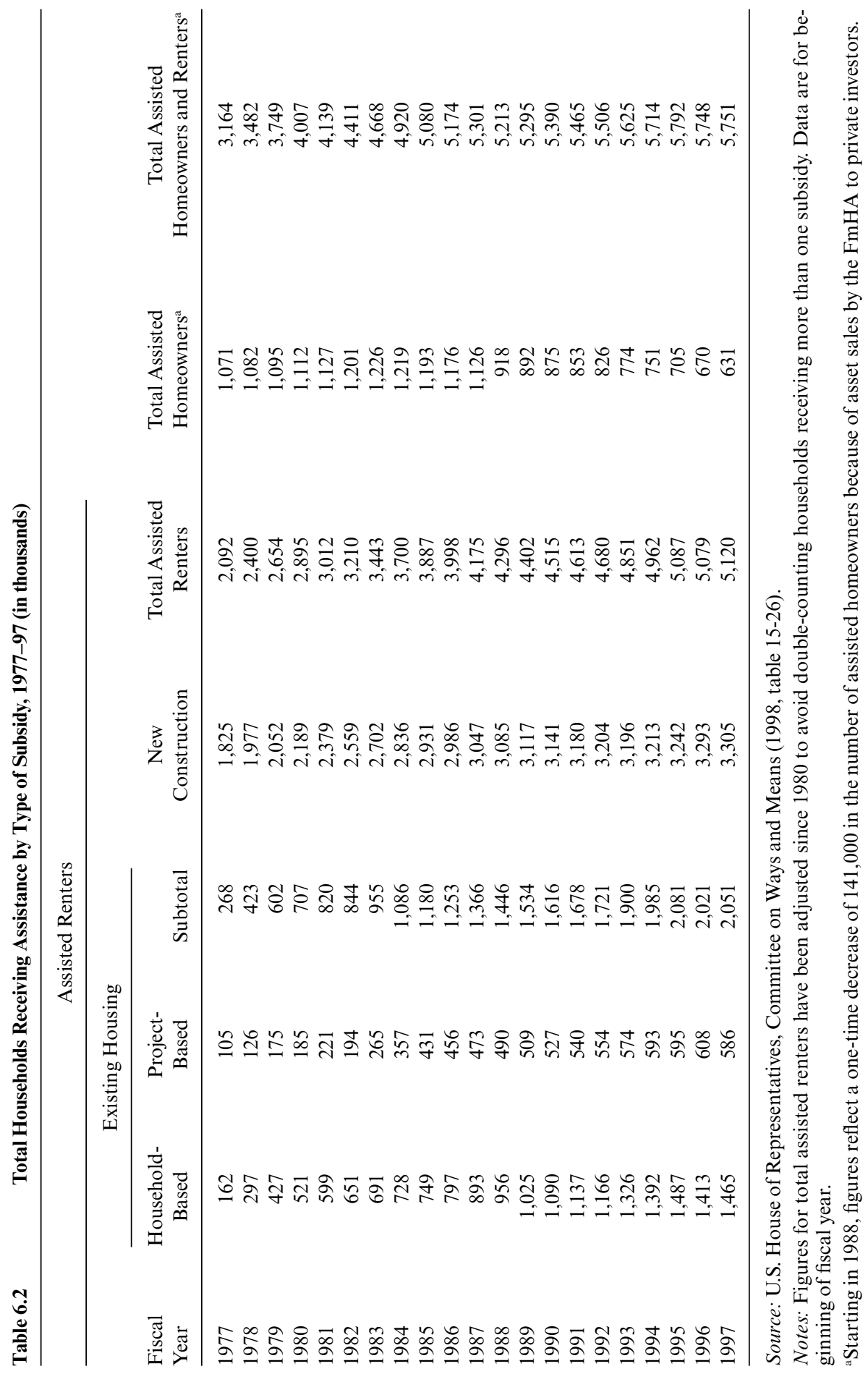


Table 6.3

Outlays for Housing Aid Administered by HUD, 1977-97

\begin{tabular}{lcc} 
& \multicolumn{2}{c}{ Outlays } \\
\cline { 2 - 3 } Fiscal Year & Current Dollars (millions) & 1997 Dollars (millions) \\
\hline 1977 & 2,928 & 7,515 \\
1978 & 3,592 & 8,660 \\
1979 & 4,189 & 9,275 \\
1980 & 5,364 & 10,687 \\
1981 & 6,733 & 12,189 \\
1982 & 7,846 & 13,273 \\
1983 & 9,419 & 15,257 \\
1984 & 11,000 & 17,096 \\
1985 & 25,064 & 37,569 \\
1986 & 12,179 & 17,813 \\
1987 & 12,509 & 17,784 \\
1988 & 13,684 & 18,684 \\
1989 & 14,466 & 18,860 \\
1990 & 15,690 & 19,484 \\
1991 & 16,898 & 19,973 \\
1992 & 18,243 & 20,936 \\
1993 & 20,490 & 22,817 \\
1994 & 22,191 & 24,079 \\
1995 & $24,059^{\mathrm{a}}$ & 25,394 \\
1996 & $25,349^{\mathrm{a}}$ & 26,032 \\
1997 (estimate) & $26,110^{\mathrm{a}}$ & 26,110 \\
\hline
\end{tabular}

Source: U.S. House of Representatives, Committee on Ways and Means (1998, table 15-28).

Notes: The bulge in outlays in 1985 is caused by a change in the method of financing housing, which generated close to $\$ 14$ billion in one-time expenditures. This amount paid off, all at once, the capital cost of public housing construction and modernization activities undertaken between 1974 and 1985, which otherwise would have been paid off over periods of up to forty years. Because of this one-time expenditure, however, outlays for public housing since that time have been lower than they would have been otherwise.

a Figures have been adjusted to account for $\$ 1.2$ billion of advance spending that occurred in 1995 but that should have occurred in 1996.

has more than tripled over the past twenty years, and table 6.4 shows that real expenditure per household has increased more than 80 percent over this period. With minor exceptions, both have increased continuously for the last twenty years.

Although there is no good reason to believe that these numbers give an erroneous view of the trends over time, it is important to realize that the outlay for a particular year is not the total cost of providing HUDsubsidized housing in that year, for several reasons. First, it does not include the many indirect subsidies involved, such as local property tax exemptions and abatements received by all public housing projects and some privately owned projects; the federal income tax exemption of interest on the bonds issued by state and local governments to finance housing projects; and the underpriced mortgage insurance received by many privately 
Per-Unit Outlays for Housing Aid Administered by HUD, 1977-97

\begin{tabular}{lcc}
\hline & \multicolumn{2}{c}{ Per-Unit Outlays } \\
\cline { 2 - 3 } Fiscal Year & Current Dollars & 1997 Dollars \\
\hline 1977 & 1,160 & 2,980 \\
1978 & 1,310 & 3,160 \\
1979 & 1,430 & 3,160 \\
1980 & 1,750 & 3,480 \\
1981 & 2,100 & 3,810 \\
1982 & 2,310 & 3,900 \\
1983 & 2,600 & 4,220 \\
1984 & 2,900 & 4,500 \\
1985 & 6,420 & 9,620 \\
1986 & 3,040 & 4,440 \\
1987 & 3,040 & 4,320 \\
1988 & 3,270 & 4,460 \\
1989 & 3,390 & 4,420 \\
1990 & 3,610 & 4,480 \\
1991 & 3,830 & 4,530 \\
1992 & 4,060 & 4,670 \\
1993 & 4,450 & 4,960 \\
1994 & 4,720 & 5,120 \\
1995 & 5,080 & 5,360 \\
1996 & 5,350 & 5,490 \\
1997 (estimate) & 5,490 & 5,490 \\
\hline
\end{tabular}

Source: U.S. House of Representatives, Committee on Ways and Means (1998, table 15-29). Notes: The peak in outlays per unit in 1985 of $\$ 6,420$ is attributable to the bulge in 1985 expenditures associated with the change in the method for financing public housing. Without this change, outlays per unit would have amounted to around $\$ 2,860$.

owned projects. ${ }^{26}$ Second, it includes outlays that are mainly used to provide housing in future years and excludes costs that are the result of past outlays. For example, if HUD pays the cost of building a public housing project this year, that outlay will appear this year. This enormously exceeds the real cost of providing the public housing units for whatever part of the current year they are available. It also greatly understates the cost of providing these units in all future years. That the development costs have been paid does not mean that the cost of using the land and structure to house low-income households is zero. These units have an opportunity cost. To the extent that few units have been built recently or the units built have been financed with upfront capital grants rather than annual payments, the real resource cost of HUD's programs is understated. HUD has built few

26. Mortgage insurance is underpriced when the present value of the losses exceeds the present value of insurance premiums. Some programs are designed to provide a subsidy in this form. 
units recently and has moved toward development grants and away from partially or fully subsidizing mortgage payments. However, without knowledge of the trend in the importance of indirect subsidies in the total cost of providing housing assistance, it is impossible to say whether the trends reported in tables 6.3 and 6.4 are understated or overstated.

Table 6.5 shows the number of units under the larger individual rental programs. The decline in the number of public housing units in recent years is due in part to the demolition of some projects, although most of the large decline between October 1997 and October 1998 is due to the exclusion of about 73,000 Indian public housing units from the total. It is a testimony to the difficulty in producing information on the number of units receiving various combinations of subsidies that this table indicates that only 38 percent of Section 236 units received rent supplements or Section 8 projectbased assistance in 1997, whereas HUD's Picture of Subsidized Households indicates that 67 percent receive Section 8 project-based assistance. The decline in the number of units under the Section 236 and Section 8 programs reflects in part the decisions of owners of some projects not to continue to participate at the termination of their contract with the government.

Table 6.6 presents information about the characteristics of the households served by HUD's four largest programs. Although household income is about the same across the four programs, the substantial differences in household sizes leads to substantial differences in per capita income. Mean household sizes are 2.8 for tenant-based vouchers and certificates, 2.4 for public housing, 2.1 for Section 236, and 1.6 for Section 8 New Construction/Substantial Rehabilitation. The latter program serves the elderly and disabled to a much greater extent than the other programs. Three-fourths of the households served by this program are in this category, as opposed to about 45 percent in public housing and Section 236 and only 34 percent with vouchers and certificates. Section 8 New Construction/Substantial Rehabilitation serves minorities to a much lesser extent than the other programs. More than half of the households served by the three other programs are members of a minority group, but only 37 percent of households served by this program are minorities. Finally, public housing projects are much more often located in neighborhoods with a high poverty rate and a high fraction of households that are minorities.

One of the most salient features of the system of housing subsidies is the extent to which it fails to offer assistance to all eligible households. ${ }^{27} \mathrm{Con}-$ sider the largest group that has been given priority for assistance by the biggest housing programs. For many years, Congress has required that public housing and Section 8 reserve a substantial majority of newly allocated units for households whose incomes are less than limits based on 50

27. See HUD (2000) for the numbers reported in this and the next paragraph. 


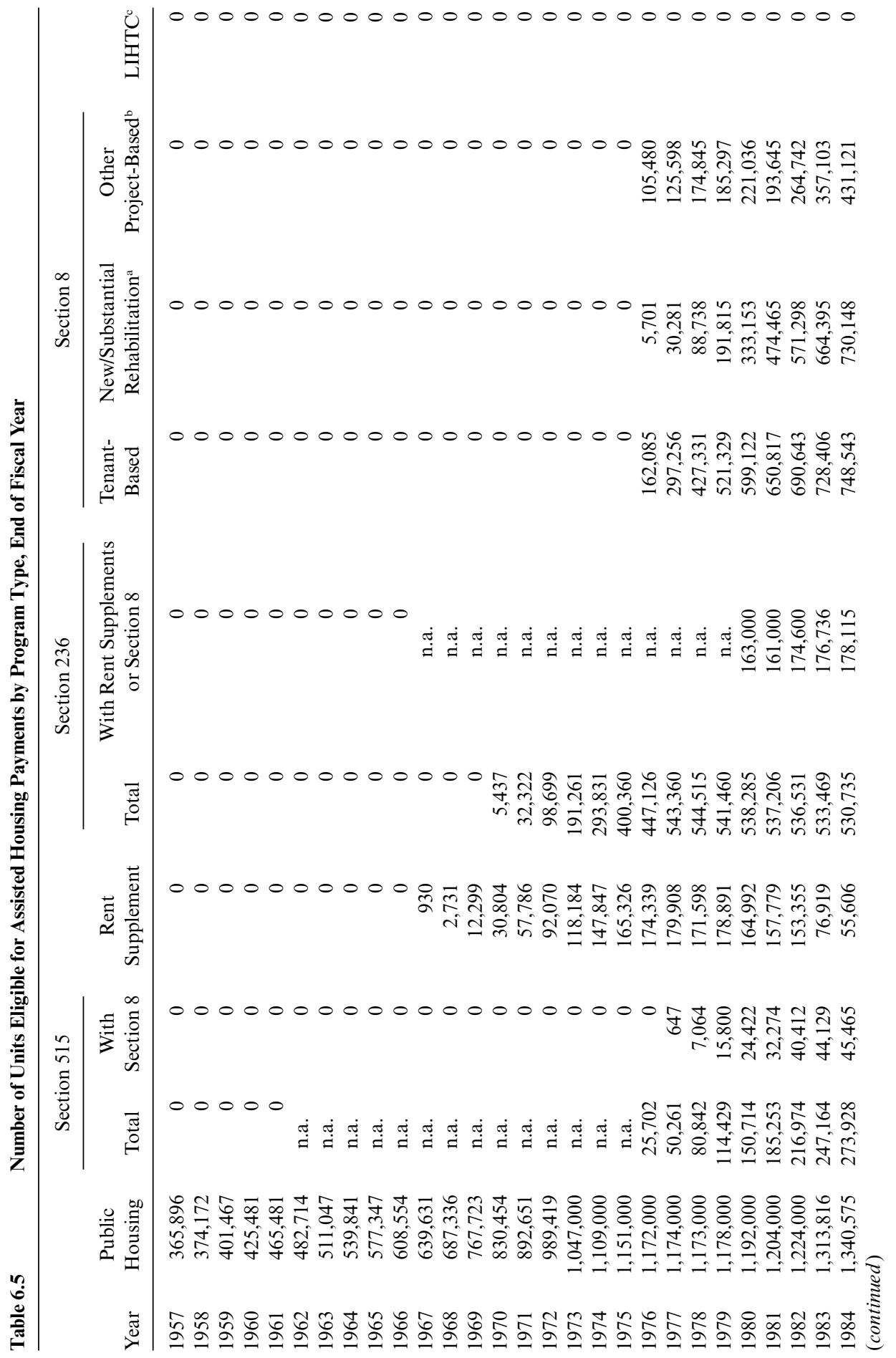




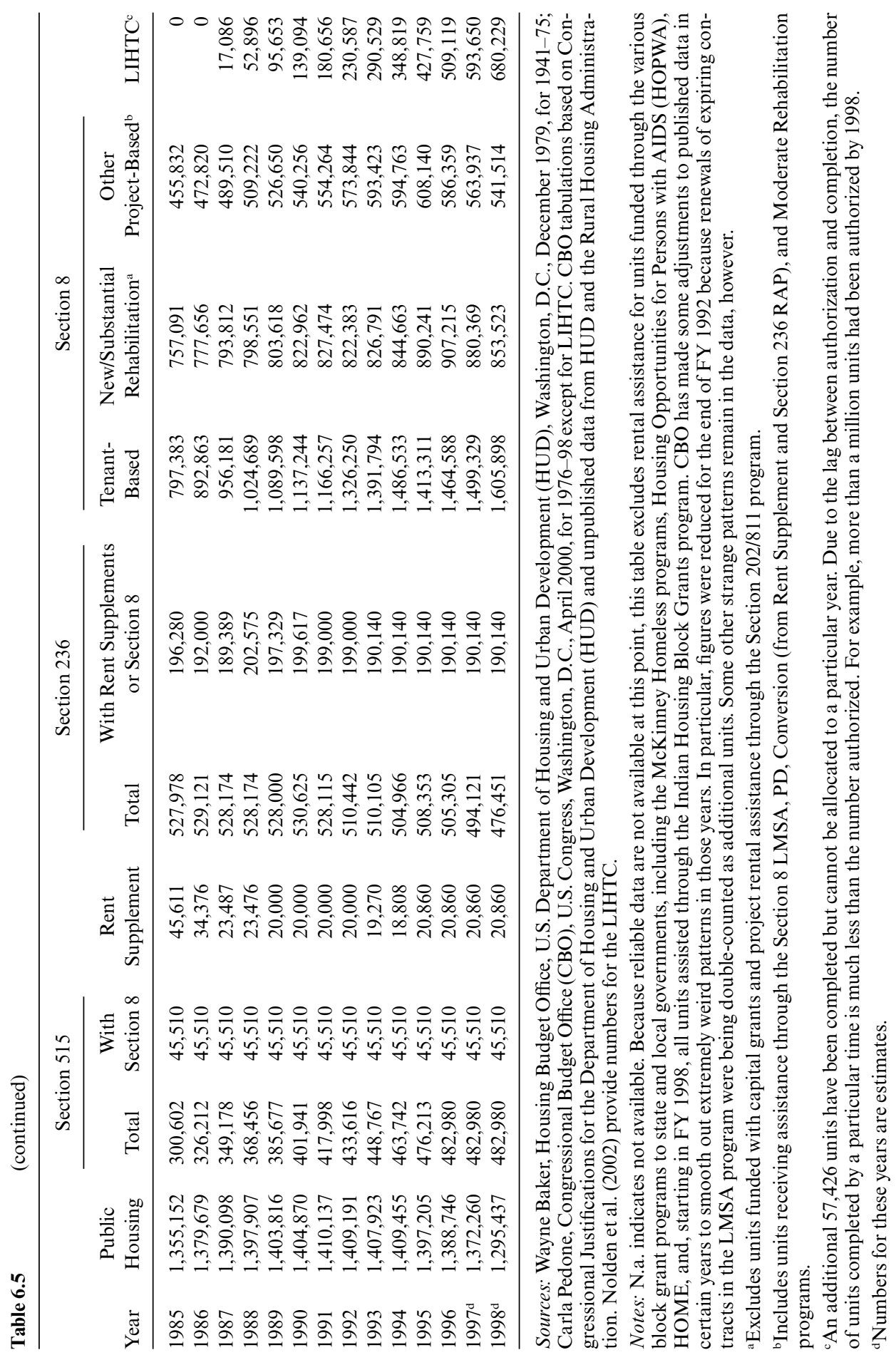




\begin{tabular}{lcccr}
\hline & $\begin{array}{c}\text { Section } 8 \\
\text { Vouchers and } \\
\text { Certificates }\end{array}$ & $\begin{array}{c}\text { Public } \\
\text { Housing }\end{array}$ & $\begin{array}{c}\text { Section } 8 \\
\text { New and Substantial } \\
\text { Rehabilitation }\end{array}$ & $\begin{array}{c}\text { Section } \\
236\end{array}$ \\
\hline Number of projects & - & 13,755 & 15,177 & 4,224 \\
Subsidized people (thousands) & 3,973 & 2,859 & 1,403 & 902 \\
Subsidized units (thousands) & 1,433 & 1,322 & 895 & 448 \\
Average rent per month, inc. utilities & 204 & 192 & 190 & 255 \\
Average household income per year & 9,100 & 8,900 & 8,900 & 10,000 \\
Average people per household & 2.8 & 2.4 & 1.6 & 2.1 \\
Per capita income & 3,250 & 3,708 & 5,563 & 4,762 \\
Neighborhood poverty rate & 20 & 37 & 20 & 21 \\
\% age 62+, head or spouse & 16 & 32 & 60 & 34 \\
\% age 62+ or disability & 34 & 48 & 74 & 43 \\
\% with children under 18 & 66 & 45 & 23 & 45 \\
\% single parent & 57 & 39 & 20 & 37 \\
\% minority total & 58 & 68 & 37 & 53 \\
\% black & 39 & 48 & 23 & 35 \\
\% Hispanic & 15 & 17 & 34 & 13 \\
Minority as \% of neighborhood & 39 & 59 & & 40 \\
\hline
\end{tabular}

Source: 1997 Picture of Subsidized Households Quick Facts (http://www.huduser.org/datasets/assthsg/ picqwik.html).

Notes: Dash indicates not applicable. Most Section 236 units (67 percent) use Section 8 Loan Management as well as Section 236 subsidy.

percent of the local median income for four-person households, with nationally uniform percentage adjustments for households of other sizes as previously described. These households account for 27 percent of all households in the country. Only 28 percent of the renters in this income group receive housing assistance. Local housing agencies have been allowed to admit households into these programs with incomes up to 60 percent higher than the limits based on 50 percent of the local median for almost twenty years. Forty-two percent of all households meet these higher income limits, and 23 percent of the renters in this larger group receive housing assistance.

Because participants whose income rises above the upper limits applicable for admission into the program are rarely terminated, because exceptions to the limits are allowed in some cases, and because some programs have higher upper income limits, many households with higher incomes receive housing subsidies under means-tested housing programs. Specifically, 10 percent of all renters with incomes between limits based on 50 and 80 percent of the local median for four-person households and the standard HUD adjustments for households of other sizes receive meanstested housing assistance. Seven percent with incomes between limits based on 80 and 120 percent of the local median and 7 percent with incomes in excess of limits based on 120 percent of the local median also receive means-tested housing assistance. 
Obviously, the overwhelming majority of eligible households do not receive housing assistance. This is not because they do not want it on the terms offered. There are long waiting lists to get into subsidized housing in all localities, and the length of the waiting list understates excess demand in many localities because housing authorities often close their waiting lists when they get sufficiently long. ${ }^{28}$

Two numbers clearly reveal the extent to which HUD's housing assistance is focused on the poorest households. Forty-three percent of the households served by HUD's programs are above the poverty line (HUD 1992, table 1-1), while 70 percent of renters below the poverty line are not served (U.S. Department of Commerce 1991, table 4-12; HUD 1992, table $1-1)$.

\subsection{Program Effects}

This section discusses what program effects should be expected based on each program's rules and the general assumptions of economic theory, and it describes the evidence on important effects of public housing, Section 236, Section 8 New Construction/Substantial Rehabilitation, and tenantbased Section 8 certificates and vouchers. To the best of my knowledge, no research on Section 515 or the LIHTC deals with the effects considered in this paper except their cost-effectiveness.

One theme of this section is that little can be said about many effects of government housing programs based on the usual assumptions of economic theory even combined with plausible additional assumptions such as the normality of housing and leisure. For example, housing programs change budget spaces in ways that do not imply that recipients will occupy better housing or work less.

\subsubsection{Cost-Effectiveness}

Since large sums of money are spent on housing subsidies and many different methods are used to deliver them, it is important to consider the cost-effectiveness of alternative approaches. When needlessly expensive methods of delivering housing assistance are used, many low-income households who could have been provided with adequate housing at an affordable rent within the current budget continue to live in deplorable housing.

All cost-effectiveness analyses of housing programs involve a comparison of the total cost of providing the housing with its market rent, an index of the overall desirability of the dwelling. For tenant-based vouchers and

28. HUD does not regularly collect data on the size of the waiting lists under any of its programs. However, a telephone survey in 1999 by HUD staff revealed that the Los Angeles Housing Authority alone had 342,000 households on its waiting list for Section 8 vouchers. 
certificates, the approach is straightforward because all of the costs associated with providing the housing during a period occur in that period and they are all in the records of the administering agency. Estimating a statistical relationship between the rent and characteristics of unsubsidized apartments and then substituting the characteristics of the subsidized units into it yields estimates of the market rents of the units occupied by subsidized households.

Dealing with construction or rehabilitation programs is more difficult because the time path of cost bears no particular relationship to the time path of the market rent of a unit, and all of these programs involve indirect costs that are not in the records of the administering agency. The most widely accepted measure of cost-effectiveness for programs of this type is the ratio of (a) the present value of the rents paid by tenants and all direct and indirect costs incurred by federal, state, and local governments to (b) the present value of the market rents of the units over the period that the units are used to house subsidized families. If a government owns the project at the time that it stops being used to house subsidized families, the present value of the project's market value at that time should be subtracted from the present value of the costs. A severe practical problem in implementing this approach is that data on the condition of the apartments in subsidized housing projects over their lives are not available, and some of the costs are difficult to obtain for each year. As a result, only one study (HUD 1974, 123-28) has fully implemented this approach. Other studies take various shortcuts or rely on strong assumptions about missing data.

This measure of cost-effectiveness focuses on effectiveness in providing housing to the recipient. It does not capture benefits or costs of a housing program to others. For example, it is possible that some housing projects make the neighborhoods in which they are located more attractive places to live. Other projects may have the opposite effect. The standard measure of cost-effectiveness captures neither positive nor negative effects of this sort.

Broadly speaking, there are three potential sources of cost-ineffectiveness of housing programs - distortions in input usage in the production of housing services, insufficient incentives for efficiency on the part of civil servants, and excessive profits to developers of private projects. This section discusses each source.

Almost all of the subsidies for housing projects are subsidies for the initial development of the project or subsidies that are independent of the mix of inputs used to provide a particular quantity of housing service. For example, some programs provide direct loans for development at belowmarket interest rates, others pay a fixed proportion of the mortgage payment on private loans, still others provide tax credits that are proportional to development cost, and some pay directly the entire development cost. Among subsidies that do not depend on input usage are rental assistance payments under the Section 8 New Construction/Substantial Rehabilita- 
tion Program and public housing operating subsidies since 1975. (Recall that the latter do not depend on the housing authority's actions.)

The preceding facts about the nature of the subsidy have led some to conclude that housing services in these projects will be produced with too much initial capital and too little of other inputs from the viewpoint of efficient production. However, since all of these programs contain limits on per-unit development cost, the net effect on input usage is ambiguous on theoretical grounds. Nevertheless, the combination of capital subsidies and development cost limits surely results in some productive inefficiency. This argument applies most directly to for-profit firms that own and operate housing for low-income households. However, to the extent that the decision makers in local housing authorities and the nonprofits who sponsor subsidized projects are interested in the well-being of their tenants rather than other taxpayers, they apply with some force to them as well.

Another incentive for inefficient production of housing services in privately owned projects is that the supplier's revenue is independent of the condition of the apartment, provided that it meets the program's minimum occupancy standards. Given the below-market rents that subsidized households are charged, there is a tremendous excess demand for these units for many years after they are built. Therefore, owners will have no trouble renting them even if they are allowed to deteriorate substantially. Just as in the case of simple rent control, this should lead to too little maintenance from the viewpoint of efficient production of housing services.

The absence of important incentives facing administrators of public housing is another source of inefficiency. Under the public housing program, government employees make all of the decisions that are made by managers of profit-maximizing firms in the private market. These include the exact specifications of the project to be built and exactly what maintenance and renovations to undertake. These decisionmakers also must monitor the performance of the employees of the housing authorities. The government managers involved do not have the same financial incentives to operate efficiently as owners of private rental housing. If they make good decisions, they are not rewarded. If they make bad decisions, they suffer no consequences over a wide range of bad decisions. Indeed, they cannot easily learn whether they have made good or bad decisions. Due to the subsidy, they will not lose their tenants unless they make extraordinarily bad decisions.

The other construction and rehabilitation programs such as Section 8 New Construction/Substantial Rehabilitation and the LIHTC provide subsidies to selected private suppliers, albeit with restrictions concerning who may live in the units, how much rent may be charged, and the like. The subsidies and restrictions are designed (or redesigned based on initial experience) to insure that the money budgeted is spent. In all cases, the result has been that many more suppliers want to participate than can be accom- 
Ratio of Present Value of Cost to Present Value of Market Rent

\begin{tabular}{|c|c|c|c|}
\hline Source & Location & Year & Ratio \\
\hline \multicolumn{4}{|l|}{ Housing vouchers } \\
\hline Mayo et al. (1980b) & Phoenix & 1975 & 1.09 \\
\hline Mayo et al. (1980b) & Pittsburgh & 1975 & 1.15 \\
\hline Wallace et al. (1981) & National & 1979 & 0.91 \\
\hline \multicolumn{4}{|l|}{ Public housing } \\
\hline Olsen and Barton (1983) & New York City & 1965 & $1.14^{\mathrm{a}}$ \\
\hline Olsen and Barton (1983) & New York City & 1968 & $1.10^{\mathrm{a}}$ \\
\hline HUD (1974) & $\begin{array}{l}\text { Baltimore, Boston, Los Angeles, St. Louis } \\
\text { San Francisco, Washington }\end{array}$ & 1971 & $1.17^{\mathrm{a}}$ \\
\hline Mayo et al. (1980b) & Phoenix & 1975 & 1.79 \\
\hline Mayo et al. (1980b) & Pittsburgh & 1975 & 2.20 \\
\hline \multicolumn{4}{|l|}{ Section 236} \\
\hline Mayo et al. (1980b) & Phoenix & 1975 & 1.47 \\
\hline Mayo et al. (1980b) & Pittsburgh & 1975 & 2.01 \\
\hline \multicolumn{4}{|l|}{ Section 8 New Construction } \\
\hline Wallace et al. (1981) & National & 1979 & $1.24^{\mathrm{b}}$ \\
\hline
\end{tabular}

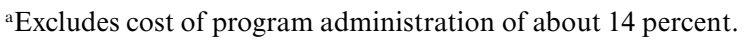

${ }^{\mathrm{b}}$ Excludes all indirect costs estimated to add 20 percent to 30 percent.

modated with available funds. For example, developers have requested three times as much money as state housing agencies have to allocate under the LIHTC in recent years. The reason for the excess demand for program funds by suppliers of housing is that those who are allowed to participate make excessive profits, provided that they do not have to pay anything for the privilege. This explains the bribery and influence peddling under these programs that periodically comes to light.

Four major studies attempt to compare the costs incurred to provide units under various housing programs with the market rents of these units. ${ }^{29}$ Table 6.7 reports the results of these studies. In assessing the results in this table, it is important to realize that the Olsen-Barton and HUD studies of public housing did not include the extra cost of administering a means-tested program (such as checking eligibility) as opposed to the cost of managing the housing. The other studies did include all administrative cost. Including all administrative costs would add about 14 percent to the total cost of public housing in the Olsen-Barton and HUD studies. Furthermore, the study of the Section 8 New Construction Program did not include any indirect costs such as the tax exemption of the interest on state

29. See Olsen (2000) for a description and appraisal of the data and methods used in these studies. This paper also discusses a study by Schnare et al. (1982) that focuses on differences in development costs across programs and contains problematic results on overall costeffectiveness. Weinberg (1982) summarizes the research in Wallace et al. (1981) and Mayo (1986) summarizes his studies of the cost-effectiveness of U.S. and German housing programs. 
bonds issued to finance state housing agency projects and the interest subsidy involved in the Tandem Plan financing of FHA-insured projects. Previous research on the magnitudes of these subsidies led Wallace and his coauthors to conclude that these indirect subsidies add 20 to 30 percent to the total cost of the projects.

With the aforementioned adjustments to insure comparability, these studies are unanimous in finding that it costs significantly more than a dollar to provide a dollar's worth of housing under construction programs such as public housing, Section 236, and Section 8 New Construction. The studies of housing certificates and vouchers show that the total costs of these programs exceed the market rents of the units by approximately the cost of administering the program. Excluding administrative cost, the two earliest studies find excess costs of public housing in the range of 10 to 17 percent. The more recent studies find excess costs for this program in the range of 65 to 106 percent. The range of the estimated excess cost of Section 236 is 33 to 87 percent, and the estimated excess cost of Section 8 New Construction/Substantial Rehabilitation is 30 to 40 percent.

These estimates almost surely understate the extent of the inefficiency of construction programs compared with tenant-based certificates and vouchers for two reasons. First, the studies using data before 1975 based their estimates of market rent on an estimated hedonic equation containing a short list of easily observed housing characteristics. Older public housing projects did not have many of the unobserved amenities that were common in the private sector. So there is good reason to expect the estimated hedonic equation to overstate the market rents of public housing units. The more recent studies are based on much more detailed data on housing characteristics and hence are likely to provide more accurate estimates of the market rents of public housing units. Second, unlike tenantbased assistance, the construction programs involve indirect subsidies that do not appear in the program's records. All studies attempt to estimate the magnitude of the major indirect subsidies. However, no study attempts to estimate the magnitude of all of the indirect subsidies. For example, some public housing units were built on land donated by federal, state, and local governments. No study has attempted to add the market value of this land to the cost of public housing. Nonprofit developers of Section 8 New Construction projects sometimes receive property tax exemptions or abatements. No study has attempted to account for this indirect subsidy.

The U.S. GAO $(2001,2002)$ provides similar results for the major active construction programs-LIHTC, HOPE VI, Section 202, Section 515, and Section 811. Using the conceptually preferable life cycle approach, the excess total cost estimates range from at least 12 percent for Section 811 to at least 27 percent for HOPE VI (GAO 2001, 3).

The GAO study will not be the last word on the cost-effectiveness of the programs studied. Like the previous studies, this study ignores some im- 
portant costs of production programs. For example, all HOPE VI projects receive substantial local property tax abatements. The GAO analysis ignores this cost to local taxpayers. It also ignores the cost of demolishing old structures on the sites of HOPE VI projects and assumes that the opportunity cost of the land is zero. Obviously, the excess cost of HOPE VI is substantially understated on these accounts. The other major shortcomings of the study are that it is based on assumptions about costs beyond the first year that are not rooted in actual program experience and it fails to account for differences in the desirability of the housing over the period of time considered. ${ }^{30}$ Instead it simply compares the average cost of units with the same number of bedrooms in the same type of location (metropolitan or nonmetropolitan). Clearly, the GAO study is improvable in many respects. However, it provides the only independent cost-effectiveness analysis of these programs.

An influential view in discussions of housing policy is that subsidized new construction is needed in localities with the lowest vacancy rates. This suggests that construction programs will be more cost-effective than vouchers in these areas. Obviously, the small number of studies of costeffectiveness and the different methodologies used in these studies preclude making any definitive judgment about this matter. Whether there are any market conditions under which construction programs are more costeffective than vouchers is surely one of the most important unanswered questions in housing policy analysis.

The GAO study contains suggestive evidence. In addition to the national estimates, the GAO collected data for seven metropolitan areas. The data for the GAO study refer to projects built in 1999. In that year, the rental vacancy rates in the seven metropolitan areas ranged from 3.1 percent in Boston to 7.2 percent in Baltimore and Dallas, with a median of 5.6 percent. The overall rental vacancy rate in U.S. metropolitan areas was 7.8 percent. So all of the specific markets studied were tighter than average. Only five of the largest seventy-five metropolitan areas had vacancy rates lower than Boston's. In each market, tenant-based vouchers were more cost-effective than each production program studied (GAO 2002, tables 7 and 8).

\subsubsection{Consumption Patterns}

Since housing programs are intended to produce particular changes in consumption of housing services compared with consumption of other

30. Lobbyists for construction programs always argue that these programs produce better housing than that occupied by voucher recipients. Although this is typically true when the units are new, it is not true over the entire time that the units are used for subsidized housing. David Vandenbroucke's unpublished research indicates that in eight of the eleven metropolitan areas studied the median market rent of voucher units exceeded the median market rents of units in both public and subsidized private projects. 
goods, knowledge of these changes is important for evaluating the programs. This section explains why the design of housing programs does not insure that the programs change consumption patterns in a way that is consistent with their justifications. It also describes the empirical evidence on the effects of the programs on overall consumption of housing services and other goods.

Ideally, a theoretical analysis of the possible effects of housing programs on consumption patterns would consider all of the other welfare programs for which a household is eligible in describing its budget space in the absence of the housing program and define preferences over at least three composites-housing, other produced goods, and leisure. This has never been done in a theoretical analysis. ${ }^{31}$ In this section, we will follow the more traditional approach in the literature, namely to assume that income is not subject to choice and that households would face a linear budget frontier defined by this income and market prices for all goods in the absence of housing subsidies. These assumptions underlie almost all empirical studies of the effects of housing programs on consumption patterns. Even with these simplifying assumptions, little can be said on theoretical grounds about the effect of any housing program on consumption of housing and other goods. For example, the public housing program could induce households to consume more housing services and consume less of other goods, more of all goods, or less housing service and more of other goods.

To see why the usual assumptions of economic theory have no important implications for consumption of housing services and other produced goods under any form of project-based assistance, consider figure 6.3. In this figure, consumption of housing services is measured on the horizontal axis and consumption of other produced goods on the vertical axis. ${ }^{32}$ The line segment is the budget line in the absence of the housing subsidy. Since housing assistance is not an entitlement, each subsidized privately owned project and each local housing authority has a waiting list. When a unit becomes available, it is offered to a household on the waiting list of an appropriate size for that apartment. This apartment provides a certain quantity of housing service $Q_{H}^{G}$ and the rent that the eligible household must pay enables it to consume a certain quantity of other goods $Q_{X}^{G}$. Normally, if the household declines the offer, it is removed from the waiting list. In some

31. Schone (1994) accounts for several major welfare programs and taxes in her empirical study of the effects of housing and other programs on consumption patterns, which will be discussed when we consider work disincentive effects.

32. The quantity of housing service is an index of all of the attributes of housing valued by consumers, including its neighborhood characteristics. In much of the empirical literature, it is measured by the market rent of the dwelling divided by a housing price index. A housing price index across areas or over time is the market rent of dwellings with the same characteristics. The more comprehensive the list of housing characteristics, the better the housing price index. A few studies based on the housing occupied immediately before and after receipt of housing assistance provide information on the program's effect on a few particular housing characteristics. 


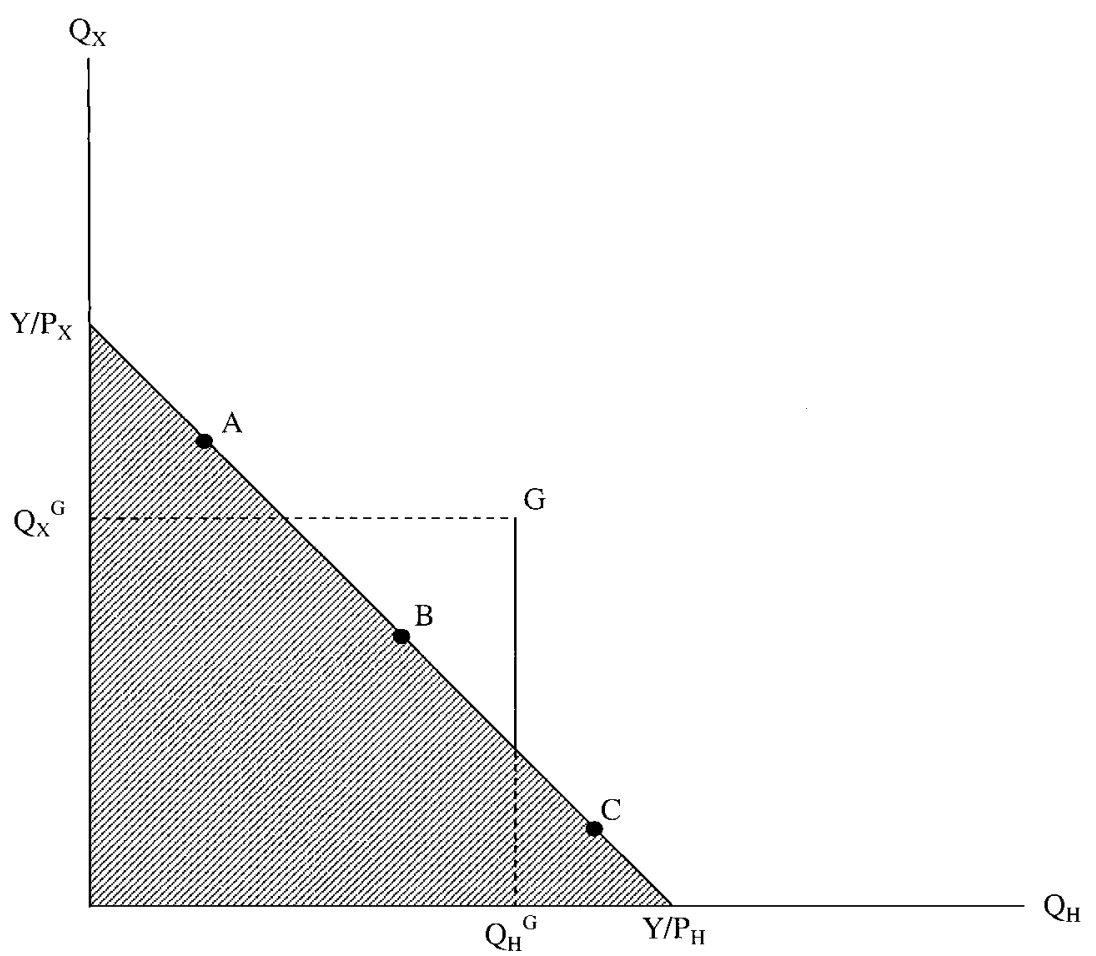

Fig. 6.3 Budget space for project-based program

cases, the household is allowed to decline several offers before removal. This does not change the argument in any fundamental way. In essence, the household is offered an all-or-nothing choice of a particular bundle. The household accepting this offer might choose bundle $\mathrm{A}, \mathrm{B}$, or $\mathrm{C}$ in the absence of the program. Therefore, the program can have any effect on the consumption bundle of a participant other than reducing its consumption of both goods.

The same conclusion is reached for any type of tenant-based assistance that has been used except for the form of housing voucher that was used between 1983 and 1999. Figure 6.4 depicts the budget spaces of eligible households who were offered assistance under the major certificate and voucher programs. In this diagram, $Y$ is the household's income and $P_{H}$ and $P_{X}$ are unsubsidized prices of housing services and other goods. Since participation in these programs is voluntary, a household that is offered assistance can consume any bundle on or below the usual budget line defined by these parameters. All of these programs of tenant-based assistance require recipients to live in apartments meeting minimum housing standards in order to receive assistance. To describe the budget space accurately, it would be necessary to decompose the housing bundle into its components be- 


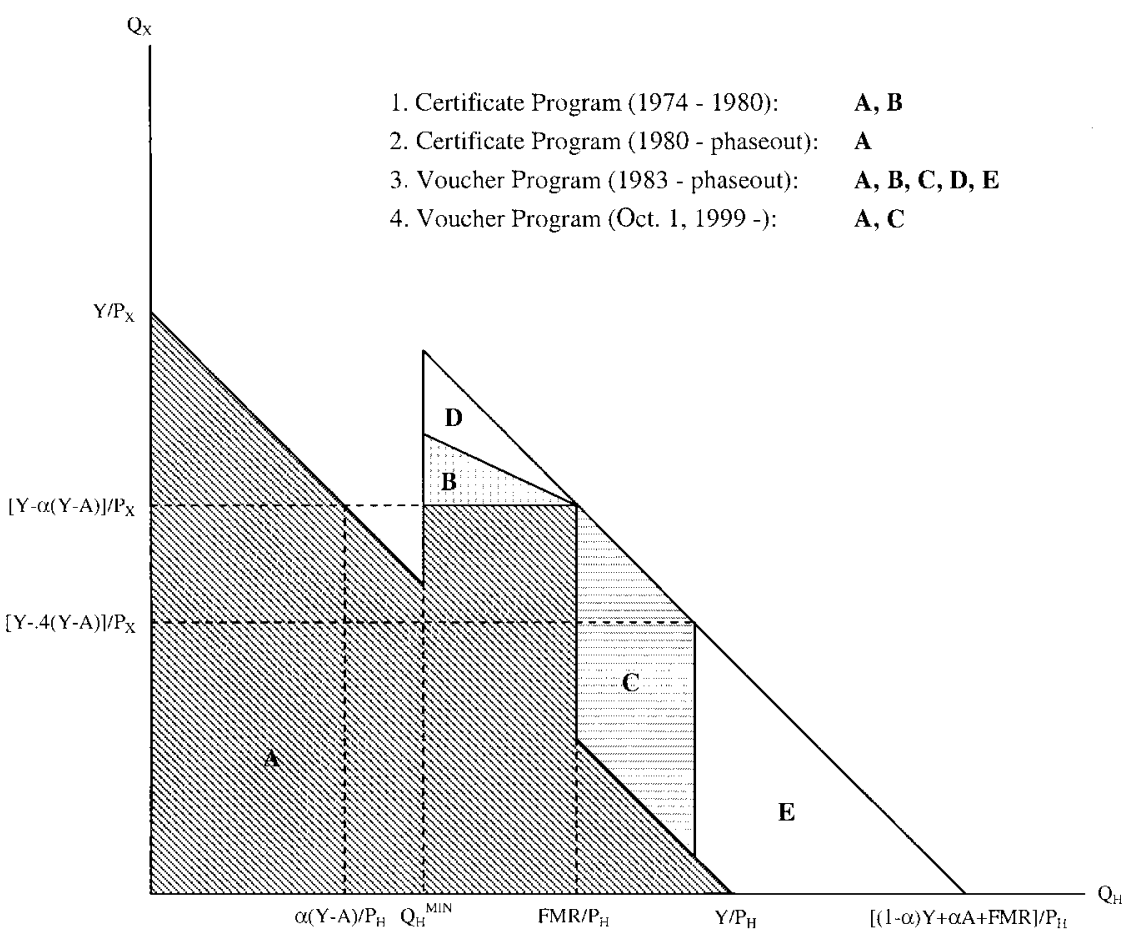

Fig. 6.4 Budget spaces under Section 8 certificate and voucher programs

cause the standards apply to some, but not all, characteristics of housing. When a scalar index of the quantity of housing services is used, this constraint places a lower limit on housing consumption $Q_{H}^{\mathrm{MIN}}$ as a condition for receipt of a subsidy. ${ }^{33}$

Under the original certificate program, participants had to occupy units renting for less than the local fair market rent (FMR) for units of the size occupied. The FMR in an area for units with a certain number of bedrooms has always been the rent at a specified percentile of the distribution of rents of a subset of units of this size. Currently, it is the 40th percentile of the rents of standard quality units occupied within the past fifteen months and not built within the last two years. ${ }^{34}$ Since there is an upper

33. In research on these programs, this minimum quantity has been measured as the market rent of units that just meet the program's standards but are minimal in other respects divided by a housing price index (Olsen and Reeder 1983; Cutts and Olsen 2002).

34. Fair market rents apply to entire metropolitan areas and their surrounding counties and groups of nonmetropolitan counties. They are published in the Federal Register each year (for example, 64FR53450) and are available on the HUD website. For the purpose of establishing FMRs, a standard quality unit is a dwelling that is adequate according to the definition used in the American Housing Survey. This characterization is based on the detailed housing characteristics collected in the survey. 
limit on the number of bedrooms that may be occupied by each household depending upon its size and composition and a ceiling rent for apartments of each size, the FMR places an upper limit FMR/ $P_{H}$ on each participant's consumption of housing services. ${ }^{35} \mathrm{~A}$ participant that occupied a unit renting for the applicable FMR paid a fraction $\alpha$ of its adjusted income $Y-A$ in rent. (The fraction is currently .3.) In this case, the subsidy was FMR $\alpha \cdot(Y-A)$ and the participant's consumption of other goods would be $[Y-\alpha \cdot(\mathrm{Y}-\mathrm{A})] / P_{x}$. If the participant occupied a unit renting for less than the applicable FMR, she paid a fraction $\alpha \cdot(Y-A) / F M R$ of the rent. Therefore, the budget space under the original certificate program was the areas $\mathrm{A}$ and $\mathrm{B}$ in figure 6.4.

The feature of the original certificate program that reduced the rent of a tenant occupying a unit renting for less than the FMR was intended to create an incentive for participants to be economical. However, surveys revealed that few participants understood the rent reduction credit, and it was eliminated in 1980. The budget space under the revised certificate program was the area $\mathrm{A}$.

The voucher program that was introduced as a demonstration in 1983 and operated simultaneously with the certificate program had a simpler structure. It paid a fixed amount toward the participant's rent provided that the participant occupied a unit meeting the program's standards. The fixed amount was PS $-\alpha \cdot(Y-A)$, where PS refers to the payment standard. The payment standard for households of each size and composition could not exceed the applicable FMR, but housing authorities could set payment standards at lower levels. ${ }^{36}$ For simplicity, figure 6.4 assumes that PS is equal to FMR. In this case, the budget space under the original voucher program is areas $\mathrm{A}, \mathrm{B}, \mathrm{C}, \mathrm{D}$, and $\mathrm{E}$.

The preceding certificate and voucher programs are being phased out in favor of a voucher program that has some features of each of its predecessors. Starting from the budget space under the most recent certificate program (the area $\mathrm{A}$ ), the new voucher program enables participants to occupy apartments renting for more than FMR, but neither increases nor decreases their subsidy if they do it. The program places an upper limit on housing consumption by limiting the tenant's contribution to rent to 40 percent of adjusted income. The tenant's contribution is simply the excess of the rent received by the landlord over the government's subsidy, FMR -

35. Given the methodology used to calculate them, differences in FMRs between areas do not reflect only geographical differences in housing prices, that is, the difference in the mean rent of identical units in different areas. Therefore, the ceiling on housing consumption has been different for identical households in different localities.

36. Since each authority was allocated a fixed amount of money, setting the payment standard below the FMR enabled it to serve more households. Under the Certificate Program, the authority was allocated a certain number of certificates. This created an incentive for each authority to lobby for higher FMRs in its area to increase the subsidies received by local residents. 
$\alpha \cdot(Y-A)$. Since $\alpha$ is currently .3, the upper limit on housing consumption is currently FMR $+.1 \cdot(Y-A)$.

If housing is a normal good, the type of voucher program in operation between 1983 and 1999 will induce households to occupy better housing than in the absence of the program, although not necessarily better than they would choose if given a cash grant equal to the amount of the housing subsidy. This type of voucher could have the same effect as the cash grant for some, all, or none of its recipients. It is easy to show that each of the other certificate or voucher programs can have any effect on consumption patterns of recipients except less of both goods.

In short, the design of housing programs does not insure that these programs change consumption patterns in a way that is consistent with their justifications. It is an empirical matter whether they have the desired effects.

The available evidence reported in table 6.8 strongly suggests that all housing programs result in substantially better housing for participants. The percentage increase tends to be greatest for new construction programs in their early years, when most of the units are new. As the average age of the units under a construction program increases, the percentage increase in housing consumption of participants declines. The results reported in table 6.9 illustrate this feature of construction programs. In 1970, the median age of public housing units was twenty-two years and the mean market rent of these units differed little from the mean rent of all unsubsidized rental units. At the same time, all Section 236 units were only a few years old. The mean market rent of these units was almost twice as great as the mean rent of all unsubsidized rental units.

Almost all housing programs at almost all times have also increased the consumption of other goods by participants. That is, participants spend less on housing than they would have spent in the absence of the program. Because the overwhelming majority of participants in each housing program pay the same percentage of their adjusted income for rent, there is little difference in expenditure on other goods among households with the same income. Expenditure on other goods under the program differs on account of different adjustments to income and possibly because the household must pay more than 30 percent of adjusted income in order to live in a privately owned subsidized project (about 25 percent of the households in privately owned HUD projects are in this category).

The numbers reported in table 6.8 indicate that the percentage increase in consumption of other goods is less than the percentage increase in housing consumption in public housing, that the opposite is true for tenantbased certificates, and that Section 236 had little effect on consumption of other goods in its early years when the rent schedule required the poorest participants to pay a flat rent exceeding 25 percent of their income. Currently, about two-thirds of the occupants of Section 236 units pay 30 per- 


\begin{tabular}{|c|c|c|c|c|}
\hline Source & Location & Year & $\begin{array}{l}\text { Housing } \\
(\%)\end{array}$ & $\begin{array}{l}\text { Other } \\
(\%)\end{array}$ \\
\hline \multicolumn{5}{|l|}{ Public housing } \\
\hline Olsen and Barton (1983) & New York City & 1965 & 58 & 17 \\
\hline Olsen and Barton (1983) & New York City & 1968 & 66 & 17 \\
\hline HUD (1974) & $\begin{array}{l}\text { Austin, Boston, Honolulu, } \\
\text { Indianapolis, Minneapolis, } \\
\text { Pittsburgh, Washington }\end{array}$ & 1971 & 82 & 19 \\
\hline HUD (1974) & $\begin{array}{l}\text { Baltimore, Boston, Los Angeles, } \\
\text { St. Louis, San Francisco, } \\
\text { Washington }\end{array}$ & 1971 & 71 & 16 \\
\hline HUD (1974) & $\begin{array}{l}\text { Boston, Pittsburgh, St. Louis, } \\
\text { San Francisco, Washington }\end{array}$ & 1971 & 59 & 5 \\
\hline Kraft and Olsen (1977) & National & 1971 & 33 & 14 \\
\hline Mayo et al. (1980a) & Phoenix & 1975 & 35 & n.a. \\
\hline Mayo et al. (1980a) & Pittsburgh & 1975 & 22 & n.a. \\
\hline Hammond (1987) & National & 1977 & 41 & a \\
\hline \multicolumn{5}{|l|}{ Section 236} \\
\hline HUD (1974) & n.a. & 1972 & 51 & 0 \\
\hline Mayo et al. (1980a) & Phoenix & 1975 & 31 & n.a. \\
\hline Mayo et al. (1980a) & Pittsburgh & 1975 & 26 & n.a. \\
\hline \multicolumn{5}{|l|}{ Section 8 New Construction } \\
\hline Wallace et al. (1981) & National & 1979 & 58 & n.a. \\
\hline \multicolumn{5}{|l|}{$\begin{array}{l}\text { Section } 8 \text { Existing } \\
\text { (tenant-based) }\end{array}$} \\
\hline Reeder (1985) & National & 1976 & 16 & 50 \\
\hline Wallace et al. (1981) & National & 1979 & 31 & n.a. \\
\hline Leger and Kennedy (1990b) & $\begin{array}{l}\text { Large urban public } \\
\text { housing authorities }\end{array}$ & 1986 & & \\
\hline Certificates & & & 59 & n.a. \\
\hline Vouchers & & & 63 & n.a. \\
\hline \multicolumn{5}{|l|}{ All programs } \\
\hline Hammond (1987) & National & 1977 & 40 & $\mathrm{a}$ \\
\hline
\end{tabular}

Notes: N.a. indicates not available. The percentage increase in consumption is the percentage increase in the real market value (that is, market value divided by an index of the prices of the goods in a category).

${ }^{a}$ Not comparable with other results due to intertemporal approach used.

cent of their adjusted income in rent because they receive project-based Section 8 subsidies, and so this program's effect on consumption of other goods is almost surely positive now.

Unfortunately, the contract reports done for HUD have consistently failed to calculate the percentage increase in consumption of other goods resulting from the programs studied or to provide the relevant mean incomes that would allow others to do it. However, these studies do indicate the dollar magnitude of the decrease in expenditure on housing. Ignoring work disincentive effects, this is the dollar magnitude of the increase in ex- 
Table 6.9

Mean Gross Market Rents of Subsidized and Unsubsidized Units, 1970

\begin{tabular}{lcccc}
\hline & Unsubsidized & Public & \multicolumn{2}{c}{ Section 236 } \\
\cline { 4 - 5 } Metropolitan Area & All Renters & Housing & New & Rehabilitated \\
\hline Baltimore & 116 & 113 & - & - \\
Boston & 135 & 125 & 245 & 206 \\
Los Angeles & 128 & 117 & - & - \\
Pittsburgh & 110 & 92 & 226 & 214 \\
St. Louis & 97 & 103 & 224 & - \\
San Francisco & 144 & 133 & 224 & - \\
Washington, D.C. & 134 & 136 & 215 & 197 \\
\hline
\end{tabular}

Source: HUD (1974, tables 18 and 31).

Notes: Dashes indicate data not available. The mean rents for all renters include the rents paid by subsidized households. Since the mean rent paid by subsidized households was below the mean rent of unsubsidized households, these mean rents understate the mean rent of unsubsidized households. However, since less than 5 percent of renters received housing assistance, the bias is surely small. Section 236 market rents are from 1972-73 data, adjusted to 1970 dollars using a national consumer price index.

penditure on other goods. These studies consistently report that housing programs lead to decreases in housing expenditure.

A careful consideration of the justifications for housing subsidies to the poor suggests that a housing program is not successful unless it induces the worst-housed households with each income to occupy better housing and consume less of other goods than they would choose if they were given cash grants involving the same subsidy. ${ }^{37}$ These are the households who undervalue housing in the eyes of paternalistic altruists. Since other programs such as food stamps and Medicaid are intended to induce households who overvalue housing in the eyes of paternalistic altruists (that is, households with excessive rent burdens) to consume more nonhousing goods than they would choose if they were given cash grants involving the same subsidy, it is not clear how housing programs should change the consumption patterns of these households.

Since substantial empirical evidence supports the view that the mean income elasticity of demand for housing is no greater than one, the results in table 6.8 strongly suggest that in aggregate occupants of public housing projects consume more housing services than they would consume if given cash grants equal to their housing subsidies. If the relevant numbers had been included in the reports of HUD's contractors, it might have been possible to make similar statements about other programs.

Although many studies compare housing consumption with and without the program, only four make the more relevant comparison between

37. The subsidy is the excess of the market value of goods consumed under the program over the market value of goods consumed in the absence of the program. 
Percentage Increase in Housing Consumption Beyond Cash Grants

\begin{tabular}{lllc}
\hline Source & \multicolumn{1}{c}{ Location } & Year & \% Increase \\
\hline Public housing & & & \\
$\quad$ Olsen and Barton (1983) & New York City & 1965 & 48 \\
$\quad$ Olsen and Barton (1983) & New York City & 1968 & 53 \\
$\quad$ Hammond (1987) & National & 1977 & 40 \\
$\quad$ Schone (1994) & National & 1984 & 49 \\
Section 8 Existing (tenant-based) & National & 1976 & 10 \\
$\quad$ Reeder (1985) & National & 1977 & 39 \\
All programs & & & \\
$\quad$ Hammond (1987) &
\end{tabular}

Note: Cash grant involved in these calculations is equal to the subsidy (that is, market rent minus tenant rent) rather than the cost to taxpayers.

housing consumption under the program and housing consumption with cash grants equal to the housing subsidies. Table 6.10 reports the results of these studies. They show that public housing, tenant-based Section 8 certificates, and the entire system of housing subsidies increase housing consumption more in aggregate than unrestricted cash grants in the aforementioned amounts.

The existing studies do not tell us whether the households whose consumption is "distorted" toward housing by these programs would have been among the worst-housed households with the same budget constraint in the absence of housing assistance. Recall that the rationale for housing subsidies implies that these are the households who should be encouraged to consume more housing than they would with a cash grant.

In deciding how many households should be subsidized to consume housing beyond the levels resulting from cash grants, it is important to realize that the overwhelming majority of households eligible for housing assistance would not live in housing with severe or moderate physical problems or more than one person per room in the absence of the assistance. (See HUD 2000, A28-A29 for HUD's definition of these terms.) In 1997, only 23 percent of unassisted eligible households lived in such housing (HUD 2000, table A5). Since the preprogram housing of recipients of housing assistance differs little from the housing of all eligible households (Wallace et al. 1981, 171), about three-fourths of all eligible households would not have these housing problems in the absence of housing programs.

\subsubsection{Neighborhoods of Assisted Households}

The landmark 1949 Housing Act established as a goal of low-income housing policy the achievement of a suitable neighborhood for all Americans, and a few studies have estimated the extent to which housing programs achieve this goal. In the absence of housing subsidies, each assisted 
Distribution of Units by Poverty Rate (\%)

\begin{tabular}{lccccc}
\hline \multicolumn{4}{c}{ Assisted Housing } & & \\
\cline { 2 - 4 } & $\begin{array}{c}\text { Public } \\
\text { Housing }\end{array}$ & $\begin{array}{c}\text { Private } \\
\text { Developments }\end{array}$ & $\begin{array}{c}\text { Certificates } \\
\text { and Vouchers }\end{array}$ & $\begin{array}{c}\text { Welfare } \\
\text { Households }\end{array}$ & $\begin{array}{c}\text { All Rental } \\
\text { Units }\end{array}$ \\
\hline Less than $10 \%$ & 7.5 & 27.4 & 27.5 & 25.3 & 42.1 \\
$10-29 \%$ & 38.9 & 50.7 & 57.8 & 51.0 & 45.4 \\
$20-39 \%$ & 17.1 & 11.5 & 9.5 & 12.1 & 6.8 \\
$40 \%$ or more & 36.5 & 10.4 & 5.3 & 11.6 & 5.7 \\
\hline
\end{tabular}

Source: Newman and Schnare (1997, table 3).

household would live in a neighborhood with certain characteristics. With housing assistance, many of these households live in neighborhoods with different characteristics. This section summarizes the evidence on the difference in neighborhood characteristics for program participants.

Before considering program effects, it is useful to provide some information on the neighborhoods occupied by households under the three broad types of rental housing assistance. Until quite recently, good national information on the neighborhoods in which subsidized households live did not exist. Sandra Newman and her collaborators have remedied this deficiency. (See Newman and Schnare 1997 for a description of the database that they have assembled and some initial results based on it.) Table 6.11 reports one of the results of their efforts. It shows that the neighborhoods occupied by public-housing tenants have many more households with incomes below the poverty line than the neighborhoods occupied by recipients of other types of project-based assistance, certificates and vouchers, and welfare recipients. Recipients of certificates and vouchers live in noticeably better neighborhoods in this regard than households in the other categories.

If households under each broad type of housing assistance would live in neighborhoods with the same characteristics as welfare-recipient neighborhoods in the absence of housing subsidies, table 6.11 would indicate the effect of housing subsidies on the neighborhoods of assisted households. However, since there are some marked differences in the characteristics of the households served by the three types of program (see table 6.6), it is not reasonable to expect that average characteristics of the neighborhoods of the households in these three groups would be the same in the absence of a housing subsidy. So we must look elsewhere for estimates of the effect of housing subsidies on the neighborhoods of assisted households.

A number of studies attempt to estimate this program effect directly by comparing the characteristics of the neighborhoods of households immediately before and after receipt of a housing subsidy. Tables 6.12 through 6.15 report some results of studies of the project-based Section 8 New Con- 
Table 6.12

Minority Percentage of All Households by Location Before and After Enrollment: Section 8 New Construction and Substantial Rehabilitation Program

\begin{tabular}{lccc}
\hline & \multicolumn{3}{c}{ Destination (\%) } \\
\cline { 2 - 4 } Origin & Central City & Suburb & All Locations \\
\hline Central city & 57 & 11 & 68 \\
Suburb & 2 & 30 & 32 \\
All locations & 59 & 41 & 100 \\
\hline
\end{tabular}

Source: Wallace et al. (1981, table 3-8).

Note: The sample size is 1,385 observations.

Table 6.13 Mean Change in Minority Concentration from Origin Tract to Destination Tract for Major Demographic Groups: Section 8 New Construction and Substantial Rehabilitation

\begin{tabular}{lcccc}
\hline Household Type & $N$ & $\begin{array}{c}\text { Mean \% } \\
\text { Minority in } \\
\text { Tract of Origin }\end{array}$ & $\begin{array}{c}\text { Mean \% } \\
\text { Minority in } \\
\text { Destination Tract }\end{array}$ & $\begin{array}{c}\text { Mean } \\
\text { Change in \% } \\
\text { Minority (\%) }\end{array}$ \\
\hline Black & 1,001 & 54 & 35 & -19 \\
Hispanic & 184 & 34 & 32 & -2.3 \\
Minority & 1,314 & 47 & 32 & -15 \\
Nonminority white & 5,918 & 7.2 & 7.0 & 0.2 \\
\hline
\end{tabular}

Source: Wallace et al. (1981, table 3-9).

Table 6.14 Income and Housing Market Characteristics of Census Tracts Occupied by Recipients Before and After Participation: Section 8 Existing

\begin{tabular}{lcc}
\hline & $\begin{array}{c}\text { Housing Voucher } \\
\text { Program }\end{array}$ & $\begin{array}{c}\text { Certificate } \\
\text { Program }\end{array}$ \\
\hline Median Family Income (1,000s) & & \\
$\quad$ Stayers & 13.3 & 13.3 \\
$\quad$ Movers' origin tract & 12.6 & 12.5 \\
$\quad$ Movers' destination tract & 13.7 & 13.5 \\
\% of families receiving welfare & 16.2 & 16.9 \\
$\quad$ Stayers & 19.3 & 19.9 \\
Movers' origin tract & 17.2 & 16.1 \\
Movers' destination tract & & 240 \\
Median monthly rent & 233 & 215 \\
$\quad$ Stayers & 217 & 234 \\
Movers' origin tract & 235 & 2.6 \\
$\quad$ Movers' destination tract & & 2.2 \\
\% of units without adequate plumbing & 2.6 & 1.9 \\
$\quad$ Stayers & 2.6 & \\
Movers' origin tract & 1.7 & \\
Movers' destination tract & & \\
\hline
\end{tabular}

Source: Leger and Kennedy (1990b, tables 4.20 and 4.22). 
Table 6.15

Change in Racial/Ethnic Concentration of Tracts Occupied by Black (Non-Hispanic) Recipients Who Moved from their Preenrollment Unit: Section 8 Existing

\begin{tabular}{lcc}
\hline & $\begin{array}{c}\text { Housing Voucher } \\
\text { Program }\end{array}$ & $\begin{array}{c}\text { Certificate } \\
\text { Program }\end{array}$ \\
\hline \% minority & 75.8 & 77.1 \\
$\quad$ Origin census tract & 73.8 & 73.7 \\
$\quad$ Destination census tract & 7.9 & 8.8 \\
\% Hispanic & 8.4 & 94 \\
Origin census tract & & 64.0 \\
Destination census tract & 63.9 & 61.2 \\
\% black & 61.9 & \\
Origin census tract & &
\end{tabular}

Source: Leger and Kennedy (1990b, table 4.25B).

struction/Substantial Rehabilitation Program and the tenant-based Section 8 Existing Housing Program. The data underlying these studies are for a random sample of units in a random sample of projects (in the case of project-based assistance) within a random sample of urban areas.

Table 6.12 reveals that 57 percent of the minority households who moved into Section 8 New Construction/Substantial Rehabilitation projects lived in the central city before and after their move and that 32 percent lived in the suburbs before and after their move. Only 11 percent of these households moved from the central city to the suburbs. So this program does not induce mass migration of minorities from central cities to suburbs.

Table 6.13 indicates that participation in this program typically induced black households to move to a neighborhood with a substantially lower minority percentage.

Tables 6.14 and 6.15 show the effects of the tenant-based Section 8 Existing Housing Program on the types of neighborhoods in which assisted households live. Many participants in this program receive subsidies without moving because their initial units already meet the program's standards or (less often) are repaired to meet the standards and they choose not to move, at least initially. The program has no immediate effect on their neighborhoods. Table 6.14 indicates that those households who move on receipt of the subsidy have fewer poor neighbors and live in neighborhoods where the housing is better. However, these effects are modest. Table 6.15 indicates that tenant-based certificates and vouchers also have a modest effect in reducing racial segregation in housing.

Finally, studies done as a part of the Experimental Housing Allowance Program indicated that public housing induces its participants to live in neighborhoods with a much higher fraction of low-income households and 
its black participants to live in neighborhoods with a significantly higher fraction of minority households (Kennedy 1980, tables 3-9 and 3-14).

All of the preceding studies estimate the immediate effect of housing programs on the types of neighborhoods in which assisted households live. No studies attempt to estimate the long-run effect of the programs on the location of households. That is, none attempt to estimate the movement of other households and the changes in the housing stock in response to the initial changes in the location of assisted households.

\subsubsection{Work Disincentives}

Since low-income housing programs are means tested, it is plausible to believe that they will have work disincentive effects. This section describes how the magnitude of housing assistance varies with labor earnings, considers what can be said based on general economic theory about work disincentive effects of housing programs, and discusses empirical research on this topic.

Low-income housing programs are means-tested in two senses. With minor exceptions, all programs mentioned in this paper have always been means-tested in the sense that there have been upper income limits for eligibility for households of each size. ${ }^{38}$ Even the programs that have not been means-tested in this sense for all participants over their entire histories have had income limits for many participants for at least twenty years primarily because some occupants of older projects now receive extra subsidies under other programs that have income limits.

The largest programs (Section 8 certificates and vouchers, and public housing) and three-fourths of the units in privately owned HUD projects are also means-tested in the sense that the magnitude of the subsidy received by a household occupying a particular dwelling depends upon its earned income (HUD 1997, 3). All units in the Section 8 New Construction Program, the largest HUD program involving privately owned projects, are means-tested in this sense. For more than fifteen years, the tenant has paid 30 percent of adjusted income in rent under these programs. ${ }^{39}$

Under some project-based programs such as the LIHTC, Section 221(d)(3), and Section 202 (older projects), the subsidy does not depend on income unless the unit or household receives a subsidy from some other source. In each of these cases, the basic program reduces the rent for each unit below the market rent, and the occupant pays this rent independent of its income. However, as far back as 1965 , some households in the projects funded under these programs have received additional subsidies that reduced their rents to a fixed fraction of their incomes, and a significant mi-

38. The primary exceptions have been the Section 202 and Section 221(d)(3) MIR.

39. This ignores several alternative rent schemes that applied to a small minority of recipients. 
nority of the current participants in these programs receives these extra subsidies. For example, about 40 percent of LIHTC units receive Section 8 assistance (GAO 1997, 40).

The basic Section 236 program was between the two extremes of proportional adjustment of rent to changes in adjusted income for all participants and no adjustment of rent for all participants. Under the basic program, all households who occupied identical units in a Section 236 project and had incomes below a certain level paid the same rent. ${ }^{40}$ If income exceeded the cutoff, the rent was 25 percent of adjusted income. Therefore, the benefit reduction rate was zero at low levels of income and .25 at higher levels. Substantial numbers of households were in each category.

Between 1965 and 1974, some, but not all, of the poorest households living in Section 236 projects received rent supplements that reduced their rents to 25 percent of their adjusted incomes over a larger range of adjusted income. After 1974, many more of the poorest households in Section 236 projects received subsidies under the Section 8 Loan Management SetAside Program that initially reduced their rents to 25 percent of their adjusted incomes and later to 30 percent. $^{41}$

In studying the work disincentive effects of housing programs, it is important to realize that the subsidy is not the same function of earnings for all households with the same characteristics, even within a given program and the same locality. The subsidy is the excess of the market rent of the unit occupied over the rent paid by the tenant. The preceding paragraphs pointed out the differences in the rents paid by households with the same characteristics under some programs. Even more important are the enormous differences in the market rents of the units occupied by similar households under all mature construction programs. The newest units under these programs are typically very good and hence have a high market rent. The worst are deplorable in part because the program's minimum occupancy standards are not always enforced. The maximum subsidy within a locality under each certificate or voucher program is the same for households with the same characteristics. However, the maximum real subsidy under this program to a household with the same real income will vary across localities because the program's guarantee (the FMR) is not the same everywhere in real terms.

For the overwhelming majority of recipients of housing assistance, the magnitude of the housing subsidy received by a household is a decreasing function of its earned income for small changes in earned income. For others, it is independent of earned income. Therefore, it seems plausible that the standard assumptions of economic theory together with the assump-

40. Within a project, the income cutoff was different for households occupying apartments of different sizes.

41. See footnote 6 . 
tion that leisure is a normal good would imply that each recipient would work less as a result of the program.

Schone (1992) has shown that this intuition is incorrect for a program such as public housing that offers a household a specified apartment for a rent that is proportional to its earned income. She does this by producing a counterexample that involves no peculiar assumptions about preferences or the budget space of the household offered a public housing unit. As usual, this theoretical ambiguity is a result of the nonlinearities of the budget frontier. Since the axioms of the theory of consumer choice do not have an implication concerning the qualitative effect of low-income housing programs on labor earnings, we must rely on empirical studies of this effect.

In the seminal study of the labor supply effects of means-tested housing programs, Murray (1980) estimated that public housing induces tenants to reduce their labor earnings by about 4 percent. Since his study predated data on the hours worked by participants in housing programs and information about multiple program participation, many highly restrictive assumptions were required to make this estimate. First, Murray assumed that leisure is separable from produced goods in household preferences. Many utility functions used in empirical research have this property. Second, he relied on a utility function defined over leisure and a composite of produced goods that was estimated ignoring all nonlinearities in budget frontiers and all differences in market prices facing households living in different localities. It also ignored differences in tastes for leisure versus produced goods across different households, thereby ignoring selection bias. Participants in housing programs may have a different taste for leisure from others. Third, in estimating the subutility function defined over housing and other produced goods, he ignored the other in-kind subsidies for which public housing participants were eligible. However, he did allow for differences in taste based on certain observed characteristics of households, and he did account for the possibility that public housing tenants have stronger than average tastes for housing by using data on these households immediately prior to entering the program to estimate the subutility function.

Since the Survey of Income and Program Participation (SIPP), it has been possible (although extremely difficult) to estimate household preferences accounting for many of the nonlinearities in budget frontiers that result from government programs and to predict the effects of changes in the parameters of these programs in a way that avoids selection bias. In the most important published attempt to estimate the work disincentive effects of housing assistance, Keane and Moffitt (1998) estimate a model of labor supply and program participation for female heads of household who are eligible for AFDC, food stamps, and housing assistance. They model Medicaid as a benefit automatically received by all participants in AFDC and 
account for federal income and Social Security taxes. The estimated model is then used to predict the effects of a wide variety of changes in the welfare system.

The treatment of housing assistance is the most problematic part of their analysis. Since estimation is extremely challenging without disaggregation of produced goods into housing and other produced goods, they did not do it. However, they recognized that housing subsidies, unlike food stamps, are worth much less to many recipients than cash grants in the amount of the subsidy. They also recognized that housing subsidies are not entitlements and that many households that want to participate are not offered assistance. Keane and Moffitt attempted to capture these aspects of reality by assuming that each household could choose to participate in a program that would provide them with a cash grant equal to an unknown fraction of the difference between the local fair market rent under the Section 8 Certificate/Voucher Program for a household with its characteristics and 30 percent of its adjusted income. That is, housing assistance was treated as an entitlement negative income tax whose known parameters are parameters of the Section 8 Certificate/Voucher Program. However, they judged the results based on this specification to be so implausible that they abandoned this approach and reestimated the model treating the housing subsidy as an exogenous component of nonlabor income for participants without attempting to explain housing program participation.

Estimation of the work disincentive effects of housing programs requires data on consumption of leisure, housing, and other produced goods for a random sample of households and the parameters of their budget spaces. Ignoring the possibility that the household alters its behavior to affect the probability that it will be offered housing assistance, the information missing from the SIPP that precludes estimation of preferences in a straightforward manner is whether a household that is not receiving housing assistance was offered it during the period under consideration and what housing assistance was offered. For example, was the household offered a Section 8 voucher? Was it offered a particular public housing unit, and what were the characteristics of that unit? (Even without this detailed information on what the household was offered, it would be possible to proceed based on a knowledge of which households rejected offers and approximations of the offer.) Accounting for the possibility that the household alters its behavior to affect the probability that it will be selected to participate in a housing program would require a model of decision making under uncertainty and a model of administrative selection. ${ }^{42}$

The best study of the work disincentive effect of a housing program is

42. Crews (1995) has developed a model of administrative selection to study the effects of housing programs on the consumption of produced goods, treating labor earnings as exogenous. 
Simulation of Cashing Out Public Housing (for current public housing recipients)

\begin{tabular}{|c|c|c|c|c|c|}
\hline \multirow[b]{2}{*}{$\begin{array}{l}\text { Original Program } \\
\text { Participation Combination }\end{array}$} & \multirow[b]{2}{*}{$N$} & \multicolumn{2}{|c|}{$\begin{array}{l}\text { Predicted Labor } \\
\text { Supply per Week }\end{array}$} & \multicolumn{2}{|c|}{$\begin{array}{c}\text { Predicted Housing } \\
\text { Consumption per Month }\end{array}$} \\
\hline & & Baseline & $\begin{array}{c}\text { Public } \\
\text { Housing } \\
\text { Cashed Out }\end{array}$ & Baseline & $\begin{array}{c}\text { Public } \\
\text { Housing } \\
\text { Cashed Out }\end{array}$ \\
\hline Public housing only & 23 & 26.28 & 27.95 & 399.88 & 283.51 \\
\hline Public housing, AFDC & 2 & 0.98 & 0 & 492.46 & 230.53 \\
\hline Public housing, food stamps & 10 & 8.57 & 6.42 & 356.95 & 242.15 \\
\hline All programs & 39 & 0 & 0 & 394.44 & 259.14 \\
\hline All public housing recipients & 74 & 9.35 & 9.56 & 393.71 & 263.65 \\
\hline
\end{tabular}

Source: Schone (1994, table 8).

also one of the most sophisticated econometric studies of the labor supply effects of any government program. In this study, Schone (1994) uses data from the SIPP to estimate the distribution of preferences defined over leisure, housing, and other produced goods for a population of femaleheaded households. These estimates account for many of the nonlinearities in the budget frontier resulting from eligibility for AFDC, food stamps, public housing, federal and state income taxes, and Social Security taxes. (She deleted households who are assisted by other housing programs from the sample because the specific program was not identified and hence she could not describe the household's budget frontier.) She then uses these estimates to predict the effects of several changes in policy. She estimates that the combined effect of AFDC, food stamps, and public housing is to reduce the labor supply of female-headed households by 42 percent and to increase their consumption of housing by 18 percent (Schone 1994, table 7). Table 6.16 reproduces her table 8 . It shows that cashing out housing programs - that is, eliminating housing programs and adding the housing subsidy to the AFDC guarantee of the participants in these programswill increase the labor supply of these households only 2 percent but will reduce their consumption of housing 33 percent.

One assumption underlying these estimates is that households who did not receive housing assistance during the last quarter of 1984 were not offered housing assistance during that period. Since it is certainly not the case that all households who are offered housing assistance accept it, this assumption is violated. For example, Kennedy and Finkel (1994) found that 13 percent of the households offered Section 8 vouchers and certificates in the early 1990s did not use them. The figure was 27 percent in the mid-1980s (Leger and Kennedy 1990). (Similar figures for public housing and subsidized privately owned projects are not available.) However, since turnover in housing programs is low and the number of assisted households was not increasing rapidly at this time, it is safe to say that only a 
minute fraction of Schone's sample declined an offer of housing assistance during the last quarter of 1984.

Of course, some households surely declined to apply for housing assistance based on the cost of participation broadly conceived and their perceptions of the likelihood of being chosen to participate in each program and, in the case of project-based assistance, the likelihood of being offered particular units. Modeling the decision to apply may enable us to estimate the distribution of taste parameters in the population with less bias and more precision. Two problems in implementing this approach are that few databases contain information on whether a household is on a waiting list for housing assistance and waiting lists are frequently closed to additional applicants. Therefore, it is incorrect to conclude that households that are not on the waiting list do not want to participate. Furthermore, many households on the waiting list decline the offer to participate in the program.

\subsubsection{Mean Benefit and Subsidy}

Since many economists are interested in the extent to which housing subsidies differ from lump-sum grants, many studies compare the recipient benefit and the subsidy. The most common measure of recipient benefit used in studies of housing programs is the equivalent variation, that is, the lump-sum grant that is just as satisfactory to the recipient as the housing program. The subsidy is the excess of the market rent of the unit occupied over the rent paid by the tenant. ${ }^{43}$ Since most housing programs change budget spaces in ways very different from lump-sum grants, we certainly expect any satisfactory measure of benefit to be less than the subsidy for almost all participants. In other words, we expect almost every household to consume a different bundle of goods than it would choose if it were given a cash grant equal to its subsidy. Therefore, the mean benefit should be less than the mean subsidy.

Table 6.17 contains the results of seven studies that estimate both the mean benefit and mean subsidy for one of the four programs or for the entire system of housing subsidies. Estimated benefits are based on estimated indifference maps or equivalently estimated Marshallian demand functions.

Clearly, there are few estimates for programs other than public housing, and there are no recent estimates for any program or for the system as a whole. The median of the estimated ratios of mean benefit to mean subsidy for public housing is .76, and 70 percent of the estimated ratios are between .71 and .81 . Based on one study apiece, the ratio is between .63 and .77 for

43. The subsidy is less than the taxpayer cost due to administrative costs and the excess of nonadministrative cost over market rent under most programs discussed in section 6.4.1. From the viewpoint of measuring the extent of the consumption distortion, benefit is best compared with the subsidy rather than taxpayer cost. 
Ratio of Mean Benefit to Mean Subsidy

\begin{tabular}{|c|c|c|c|c|c|}
\hline & Location & Year & Measure & Sample & Ratio \\
\hline \multicolumn{6}{|l|}{ Public housing } \\
\hline Olsen and Barton (1983) & New York City & 1965 & EV & 1366 & 0.77 \\
\hline Olsen and Barton (1983) & New York City & 1968 & $\mathrm{EV}$ & 1515 & 0.73 \\
\hline Murray (1975) & 7 cities & 1968 & $\mathrm{EV}$ & 1388 & \\
\hline Cobb-Douglas & & & & & 0.81 \\
\hline CES & & & & & 0.84 \\
\hline Kraft and Olsen (1977) & $\begin{array}{l}\text { Boston, Pittsburgh, } \\
\text { St. Louis, San Francisco, } \\
\text { Washington, D.C. }\end{array}$ & 1972 & EV & 333 & 0.73 \\
\hline Clemmer (1984) & 33 SMSAs & 1977 & EV & $>20,000$ & \\
\hline Cobb-Douglas & & & & & 0.92 \\
\hline Stone-Geary & & & & & 0.80 \\
\hline Linear demand & & & & & 0.71 \\
\hline Nonlinear demand & & & & & 0.76 \\
\hline Hammond (1987) & National & 1977 & EV & 804 & 0.64 \\
\hline \multicolumn{6}{|l|}{ Section 8 New Construction } \\
\hline Schwab (1985) & 13 metro areas & 1979 & $\mathrm{CV}$ & 167 & \\
\hline $\begin{array}{l}\text { Log-linear } \mathrm{H} \text { expenditure } \\
\text { function }\end{array}$ & & & & & 0.63 \\
\hline $\begin{array}{l}\text { Linear } \mathrm{H} \text { expenditure } \\
\text { function }\end{array}$ & & & & & 0.77 \\
\hline \multicolumn{6}{|l|}{ Section 8 Existing (tenant-based) } \\
\hline Reeder (1985) & National & 1976 & EV & 1,099 & 0.83 \\
\hline \multicolumn{6}{|l|}{ All programs } \\
\hline Hammond (1987) & National & 1977 & EV & 1,088 & 0.61 \\
\hline
\end{tabular}

Notes: $\mathrm{EV}=$ equivalent variation; $\mathrm{CES}=$ constant elasticity of substitution; $\mathrm{CV}=$ compensating variation; SMSA = standard metropolitan statistical area.

Section 8 New Construction/Substantial Rehabilitation, .83 for tenantbased Section 8 Existing, and .61 for the system as a whole. In assessing the significance of these results for public policy, it is important to realize that mean recipient benefit will be less than the mean subsidy for any successful housing program.

\subsubsection{Distribution of Benefits}

Many taxpayers care about how benefits are distributed across recipients of housing assistance. They are interested in how mean benefit varies with household characteristics and the variance in benefit among households with the same characteristics. This section explains why little can be said about these matters based on economic theory, and it describes the results of empirical research.

Little can be said on the basis of the program's rules and the general assumptions of economic theory about how mean benefit will vary with household characteristics under any of the programs even within a single 
locality. Since larger households are entitled to larger apartments under the programs considered, the subsidy will be greater for larger households on this account. However, since larger units under new construction programs may typically be in worse condition or in worse neighborhoods than smaller units, they are not necessarily better overall. Therefore, the mean subsidy is not necessarily greater for larger households. The certificate and voucher programs provide a larger maximum subsidy to larger households within a locality. However, if larger households experience a larger consumption distortion than smaller households, they could receive a smaller benefit even though they receive a larger subsidy.

Similarly, the design of housing programs does not insure that mean benefit will vary with household income within a locality in a particular manner. For all units under many project-based housing programs and many units under the rest, the rent that the tenant pays varies directly with income among households of the same size. Therefore, if all households of a particular size served by a program lived in apartments with the same market rent, the subsidy would be larger for the poorest households of that size. Under all variants of tenant-based Section 8 , the maximum subsidy varies inversely with income among households of the same size. However, it is far from the truth that all households served by a mature construction program (that is, a construction program that has been in existence for many years) occupy housing with the same real market rent. Furthermore, a larger subsidy does not imply a larger benefit. If poorer households experience a larger consumption distortion than richer households, they could receive a smaller benefit even though they receive a larger subsidy.

Table 6.18 summarizes the results of regressions of estimated benefit on household characteristics in which a linear relationship between mean benefit and income, family size, age, race, and other characteristics are assumed. ${ }^{44}$ Some results are consistent across the studies. In public housing, tenant-based Section 8, and the system as a whole, the mean benefit is larger for poorer households that are the same with respect to other characteristics. Similarly, mean benefit is larger for larger households. These results continue to hold when the authors allow for the possibility of a nonmonotonic relationship by including income and family size squared. The results are less consistent for race and age of the head of the household. The coefficients have different signs in different studies, they are often statistically insignificant, and the magnitudes of the coefficients indicate small differences in mean benefit among otherwise similar households who differ in these respects.

44. Except for Kraft and Olsen, all of the studies used real benefit and income in their analyses. That is, they divided money benefit and income by a cross-sectional price index. Since Kraft and Olsen's study is based on data for five of the country's largest metropolitan areas, it is not clear that taking account of overall differences in prices would have had much effect on their results. 


\begin{tabular}{lcccccr}
\hline & Income & Family Size & Black & Age & SE/Benefit & Sample \\
\hline Public housing & & & & & & \\
$\quad$ Olsen and Barton (1983), 1965 & $-* *$ & $+* *$ & - & - & 0.38 & 1,366 \\
$\quad$ Olsen and Barton (1983), 1968 & $-* *$ & $+* *$ & - & - & 0.43 & 1,515 \\
$\quad$ Murray (1975) & - & + & $+* *$ & $+* *$ & & 1,388 \\
$\quad$ Kraft and Olsen (1977) & $-* *$ & $+* *$ & $-* *$ & $-* *$ & 0.93 & 333 \\
$\quad$ Hammond (1987) & $-* *$ & $+* *$ & - & $+* *$ & 0.89 & 804 \\
$\begin{array}{l}\text { Section 8 Existing (tenant-based) } \\
\quad \text { Reeder (1985) }\end{array}$ & $-* *$ & $++^{* *}$ & - & + & 0.42 & 1,099 \\
All programs & & & & & & \\
$\quad$ Hammond (1987) & $-* *$ & $+* *$ & + & $+* *$ & 1.23 & 1,088 \\
\hline
\end{tabular}

Notes: This table summarizes the results from multiple regression analyses in several articles. In each case, the benefit is regressed on the variables presented in the first four columns and other variables. Olsen-Barton and Kraft-Olsen included sex of the head of the household; Hammond included sex and education of the head and dummy variables for region of the country and size of the locality; and Reeder included dummy variables for sex of the head, other minority, and nonmetropolitan residence as well as an overall price index and the squares of income and family size. In Murray, age is a dummy variable that indicates whether the head is 62 years or older. Murray also includes dummy variables for different household compositions rather than a single variable for family size. The signs presented in the table indicate whether mean benefit varies directly $(+)$ or inversely $(-)$ with the household characteristic. The fifth column presents the standard deviation of the error term divided by the mean benefit, as a measure of the amount of variation present. Finally, the last column gives the number of observations used in the regression.

*The coefficient was statistically significant at the 5 percent level.

Two other noteworthy results emerged from these analyses. First, when Murray (1975) included dummy variables for the different cities represented in his data in the regression equation, he found substantial differences in the real mean benefit of public housing for households with the same characteristics living in different urban areas. In her study of public housing and the entire system of housing subsidies, Hammond (1987) also found substantial differences in real mean benefit for otherwise similar households living in different regions and in places with different degrees of urbanization. Reeder (1985) found large differences in the real mean benefit of the Section 8 Existing Housing Program between otherwise similar households living in expensive and inexpensive locations. Second, when Reeder included in the regression equation a measure of the household's taste for housing based on its preprogram housing consumption, he found that households with the strongest taste received the largest benefit from the Section 8 Existing Program.

\subsubsection{Participation Rates}

Since taxpayers with any interest in helping low-income households are more interested in helping some types of households than others, information on participation rates of different types of households is useful for dis- 
cussions of housing policy. This section summarizes the evidence on this matter.

Reeder (1985, table 6) presents the percentage of households in each income and family size class who participate in any HUD program in 1977. The highest participation rate in any of the seventy-seven classes was less than 25 percent. The regularities are that, for any family size, the participation rate first rises and then falls as income increases. For unknown reasons, the poorest households of each size have very low participation rates. Within each income class, participation rates are highest for one-person households, reflecting the strong preference received by the elderly in housing programs.

Wallace et al. (1981, figure S-3 and table 2-8) compare the fraction of eligible households and participants in the Section 8 Existing and New Construction programs with particular characteristics. These comparisons do not hold other characteristics constant. For Section 8 Existing they find that in 1979 the percentage of participants who were elderly was about the same as the percentage of eligibles in this category, that minorities were a slightly larger fraction of participants than eligibles, and very low-income households were a noticeably larger fraction of participants than eligibles. ${ }^{45}$ For Section 8 New Construction, the elderly, whites, females, and small families were greatly overrepresented in the sense that they were a higher fraction of participants than eligibles.

Olsen and Barton $(1983,325)$ use a linear probability model to estimate how the participation rate in public housing in New York City in 1965 and 1968 varied with the household's income and size and with the age, race, and sex of the head of the household. (At that time, public housing accounted for almost all subsidized housing for the poor in the city.) The most striking finding is that blacks had a much higher participation rate (about 20 percentage points) than whites with the same other characteristics. No attempt has been made to determine the explanation for this finding. Participation also increased noticeably with family size (about 4 percentage points per person).

In her attempt to account for both self- and administrative selection in estimating the preferences of recipients of housing subsidies and the benefits that they receive from housing programs, Crews (1995) used data from the eleven metropolitan areas in the 1987 American Housing Survey to estimate a probit model explaining whether a household receives housing assistance. Her explanatory variables reflect participation costs broadly conceived and the factors involved in the preference systems of housing authorities. She found that the poorest households, nonwhites, food stamp

45. Recall that in HUD's terminology very low-income households are not necessarily poor. A family of four is considered to have a very low income if its income is less than 50 percent of the local median. 
and welfare participants, and the unemployed had higher participation rates that were statistically significant at the 1 percent level. The elderly have a much higher participation rate that is statistically significant at the 5 percent level.

\subsubsection{Market Prices}

It is often argued that housing programs will have effects on the rents of unsubsidized units with specified characteristics throughout the housing market. For example, it has been argued that housing vouchers will lead to a higher demand and hence higher rents for units that just meet the standards of the housing program and lower demand and hence lower rents for the worst units because these units will be abandoned by households who receive vouchers. This argument is certainly well founded on economic theory, at least in the short run. Others argue that new construction programs will lead to lower prices for existing apartments. If the new construction comes as a complete surprise to private suppliers, this is also a clear implication of standard economic theory. However, if the new construction under the program is completely anticipated by private suppliers, the opposite effect is to be expected. To the extent that subsidized construction programs lead to greater production of housing, they drive up the prices of inputs that are most important in the production of housing and thereby increase the cost of producing housing with any specified characteristics.

With the exception of Susin (2002), there are no studies of the effects of any of the programs under consideration on market rents of units with a given set of characteristics. ${ }^{46}$ NBER and Urban Institute simulation models have been used to study the effects of hypothetical programs bearing some resemblance to the programs under consideration (De Leeuw and Struyk 1975; Kain 1981). The Housing Allowance Supply Experiment did study the effect on market prices of an entitlement housing voucher program similar to the Section 8 voucher program in operation between 1983 and 1999. This study found little effect on the market rents of units of any type (Barnett and Lowry 1979; Mills and Sullivan 1981; Rydell, Neels, and Barnett 1982). For units that were significantly below standards prior to the experiment, rents fell. For modest units meeting the standards or falling slightly below them, rents rose. If an entitlement housing allowance program for which 20 percent of households were eligible had no discernible effect on housing prices, it is perhaps reasonable to conclude that existing tenant-based programs have little effect.

Susin (2002) reports results inconsistent with this conclusion and with the implications of standard economic theory. Since vouchers induce re-

46. Studies of the effects of housing programs on the rents of units in the immediate neighborhoods of subsidized housing deal with a different issue. These studies measure the magnitude of nonpecuniary external effects rather than market effects due to changes in the pattern of demand and supply. 
cipients to vacate the worst housing and occupy housing in the middle of the quality distribution, this program should decrease rents of the worst apartments and increase rents of units of average quality. Susin finds that unsubsidized poor households in metropolitan areas with more vouchers per poor household pay higher rents for units that are the same with respect to many observed housing characteristics.

To obtain this result, he first uses data from the 1993 National American Housing Survey to estimate a hedonic regression explaining the rent of unsubsidized apartments as a function of housing characteristics and dummy variables for combinations of metropolitan area and income group, for example, the poorest households in Oakland. ${ }^{47} \mathrm{He}$ interprets differences in the coefficients of the dummy variables for a particular type of household across metropolitan areas as reflecting differences in the price of identical housing. ${ }^{48}$ For each of the three income classes separately, he regresses these estimated coefficients on the number of vouchers per poor household and a few other potential determinants of the price of identical units.

The reason for the discrepancy between Susin's findings and the implications of the usual theoretical argument about the effects of vouchers on rents is not clear. His results concerning the differences across income groups in the rents of units with the same observed characteristics in the same metropolitan area suggest the importance of unobserved characteristics. He finds that households with higher incomes consistently pay higher rents. The only plausible explanation for this result is that richer households living in apartments that are the same with respect to observed characteristics occupy units that are better with respect to unobserved characteristics. So one possible explanation for Susin's puzzling result is that unobserved housing characteristics are correlated with the number of vouchers per poor household. Since assertions about the effects of different types of housing programs on market prices are influential in discussions of housing policy, additional studies of this question are important.

\subsubsection{Tangible External Benefits}

Many of the alleged tangible external benefits and costs of particular types of housing program would accrue to neighbors of subsidized households. To the extent that they existed, these external benefits and costs

47. The division of the population into thirds is not based entirely on income, but it is based on household rather than housing characteristics. This is important because the theory explaining the market effects of housing vouchers divides the housing market based on housing characteristics. Most importantly, it distinguishes between units that do and do not meet the program's housing standards. It is important to realize that many households in the lowest third of the income distribution live in units in the middle third of the housing desirability distribution. Many households in the middle third of the income distribution live in units in the lowest third of the housing desirability distribution.

48. Susin $(2002,126)$ recognizes the importance of unobserved housing characteristics, but this does not affect his procedures or interpretation of results. 
would be reflected in neighboring property values. Although the oldest study of this matter was conducted more than forty years ago, there have been relatively few studies over the years. ${ }^{49}$ Until recently, these studies have usually been limited to a small number of projects in one city or based on crude methods and data. Recent advances in software for analyzing geographical data have led to several detailed analyses based on data on sales of all unsubsidized single-family units and the location of all subsidized households or projects in several large metropolitan areas.

Lee, Culhane, and Wachter (1999) studied the effects of all major urban rental-housing programs. ${ }^{50}$ They find small positive effects on neighboring property values on average for some programs and small negative effects for others. Galster, Tatian, and Smith (1999) find statistically significant effects of the occupancy of units by recipients of Section 8 certificates and vouchers on neighborhood property values. The direction of the effect depends on the nature of the neighborhood and the concentration of program participants in the neighborhood, and the magnitudes are relatively small.

\subsubsection{Other Issues}

One of the most active areas of research on housing policy over the past few years has been the effect of offering vouchers to occupants of public or private subsidized projects located in central city neighborhoods with high concentrations of poverty on the condition that they move to low-poverty neighborhoods. This research is based on data from HUD's Moving to Opportunity (MTO) Demonstration Program that has been in operation since 1994 in Baltimore, Boston, Chicago, Los Angeles, and New York. Eligible participants were randomly assigned to one of three groups: those who received a Section 8 voucher on the condition that they occupy a unit in a census tract with a poverty rate of less than 10 percent as well as adhering to the other program requirements, those who received regular Section 8 vouchers, and those who continued to receive their current projectbased assistance. Households in the first group receive counseling and assistance in finding a private unit, and the experiment was not designed to estimate the effect of this intervention separately from other aspects of the offer.

Although the MTO Demonstration affects few households (about 1,300 ), its carefully controlled experimental design should permit definitive answers to the main questions posed. The research to date indicates

49. See Galster, Tatian, and Smith (1999) for a review of the literature.

50. They incorrectly assume that the FHA-assisted units in their data are owner-occupied units. In fact, these are units in privately owned subsidized rental projects under programs such as Section 221(d)(3) and 236 whose mortgages are insured by the FHA. Therefore, their conclusions about the effect of homeownership programs on neighboring property values is not supported by their results. 
that offering households Section 8 vouchers on the condition that they move to low-poverty neighborhoods (combined with assistance in finding a unit) reduces welfare dependency by adults and violent crimes by teenagers in recipient households and increases the educational attainment of younger children in these households. They are also less likely to be the victims of crimes or suffer injuries or asthma attacks (Katz, Kling, and Liebman 2001; Ludwig, Ladd, and Duncan 2001). Kling's web page (http://www.wws.Princeton.EDU/ kling/mto/) contains a comprehensive account of the experiment and research based on it.

Other important issues dealt with in the literature on housing policy are the extent to which subsidized new construction reduces unsubsidized construction (Murray 1983, 1999), the effect of subsidized housing on homelessness (Early 1998), the effect of living in public housing on the educational attainment of children and their earnings as adults (Currie and Yelowitz 2000; Newman and Harkness 2002), and the effect of public housing waiting lists on intra-urban mobility (Painter 1997). The former is particularly important because erroneous views about this matter contribute importantly to bad policy.

\subsubsection{Experimental Housing Allowance Program}

No discussion of housing policy research would be complete without some mention of the Experimental Housing Allowance Program (EHAP). The major goals of EHAP were to determine the market effects of an entitlement program of tenant-based housing assistance and the effects of various types of such assistance on household choices. Congress authorized this program in 1970, planning for the experiment occurred in the early 1970s, data were collected during the mid-1970s, and the final reports were completed in the late 1970 s and early 1980 s. The experiment cost almost $\$ 200$ million (that is, more than $\$ 500$ million in 2000 prices); research and data collection accounted for almost half of this amount. ${ }^{51}$ The research firms that ran the experiments issued more than 300 reports, technical notes, and professional papers. As a result of these expenditures, we know more about the effects of the experimental programs studied than any established housing program.

The experiment had four components: the Supply Experiment, the Demand Experiment, the Administrative Agency Experiment, and the Integrated Analysis. The first two were the largest and most important.

The primary purposes of the Supply Experiment were to determine the market effects of an entitlement program of household-based assistance, such as its effects on the rents of units with specified characteristics and how suppliers alter their units in response to the program. The Supply Experiment research still accounts for the bulk of what is known about these

51. Sadly, HUD lost all of the data that had been so carefully collected and documented. 
matters. The RAND Corporation conducted the Supply Experiment. The experiment involved operating entitlement housing allowance programs in the Green Bay and South Bend metropolitan areas. At the time of the experiment, Green Bay had few minorities and a very low vacancy rate. South Bend had a large minority population and a high vacancy rate. About 20 percent of the households in each area were eligible for housing assistance. Unlike established housing programs, both renters and homeowners could participate. These households were offered a cash grant on the condition that they occupy housing meeting certain standards. These payments could continue for up to ten years provided that the household remained eligible.

The Demand Experiment, conducted by Abt Associates in the Pittsburgh and Phoenix metropolitan areas, was primarily intended to see how recipients would respond to different types of household-based housing assistance and, for a given type, to different program parameters. To this end, eligible households were assigned at random to the different programs or to a control group that was paid a small amount of money to provide needed information. One type of housing assistance offered eligible households a cash grant under the condition that they occupy housing meeting certain standards, another offered a cash grant under the condition that they spend at least a certain amount on housing (two different amounts were tested), and another offered the same cash grant with no strings attached. Two other plans offered to pay different fractions of the household's housing expenditure with no other strings attached. Since the Demand Experiment provided subsidies for only three years and large changes in housing consumption have a large fixed-cost component, the Demand Experiment results undoubtedly understate the responsiveness to a permanent program (Bradbury and Downs 1981, 367-68).

The most influential Demand Experiment research went beyond a comparison of different types of household-based assistance. It compared the effects of the minimum-standards housing allowance program with the major established housing programs in existence at the time, namely public housing, Section 236, and Section 23. The results of some of this research are reported earlier in this paper.

In the Integrated Analysis, the Urban Institute helped to design all of the experiments and used data from all of the experiments to analyze many of the same questions considered by the contractors operating the experiments. The Administrative Agency Experiment conducted by Abt Associates focused on the behavior of local administrative agencies in operating an allowance program. Unlike the Demand Experiment, it was not a controlled experiment.

The best introductions to this vast literature are the final reports of the Supply Experiment, the Demand Experiment, and the Integrated Analysis (Lowry 1983; Kennedy 1980; Struyk and Bendick 1981), an edited volume 
containing summaries of the findings by the major contributors to EHAP research (Friedman and Weinberg 1983), an edited volume containing evaluations of this research by outside scholars (Bradbury and Downs 1981), a monograph containing some of the more technical results on consumer behavior from the Demand Experiment (Friedman and Weinberg 1982), and HUD's 1980 summary report (HUD 1980).

Although it is impossible to present a detailed review of the findings here, it is possible to state a few of the most important results for housing policy. Since the only type of tenant-based housing assistance studied in EHAP that has been used in an established program is the cash grant conditional on occupying a dwelling meeting certain housing standards, and both the Supply and the Demand experiments studied this type of program, the summary below will focus on it. ${ }^{52}$

The experiments revealed that many unsubsidized low-income households live in housing meeting reasonable standards. About half of the eligible families in the Supply Experiment occupied housing meeting its standards, and about a fourth of the eligible families in the Demand Experiment sites occupied housing meeting its more stringent standards prior to receiving assistance. Even at the lowest income levels, many households occupied units meeting the standards of the Demand Experiment, which suggests the importance of preferences in determining whether poor households meet housing standards. Not surprisingly, households whose units met the standards prior to the program were much more likely to participate in the minimum-standards housing allowance program. They could receive a subsidy without moving or getting their landlords to improve their apartments.

In estimating the cost of an entitlement housing assistance program, it is often assumed that all eligible households would participate. The Supply Experiment revealed that this assumption could be far from the mark. Although the entitlement housing allowance programs in Green Bay and South Bend were heavily publicized, the participation rate leveled off at about a third after three years. It was about 41 percent for eligible renters and 27 percent for eligible homeowners. The primary reasons for the low participation rates are easy to understand. Since the subsidy declines linearly with income until the upper income limit is reached and the density of eligible households increases with income, many eligible households were entitled to small subsidies. Many others who were eligible for somewhat larger subsidies had to move to get them because their apartments were substantially below the program's minimum standards. Many house-

52. The Section 8 Voucher Program implemented in 1983 and currently being phased out is a program of this type. (See figure 6.4.) Since this program does not have the same specific parameters (housing standards, real guarantee, and benefit reduction rate) as the programs studied in the experiments, and since participation in the Section 8 Voucher Program depends importantly on administrative selection, it should not be expected to have the same quantitative effects as the experimental programs. The best sources of information about the effects of the Voucher Program are the detailed studies commissioned by HUD (Leger and Kennedy 1990; Kennedy and Finkel 1994). 
holds eligible at a point in time were only briefly eligible. Finally, despite the heavy publicity, 17 percent of eligible households had not learned about the program by the end of its third year. Obviously, we should not conclude that the participation rate in any entitlement minimum-standards housing allowance program would be a third. This is heavily dependent on the generosity of the subsidy and the minimum standards. It is possible to have an expensive entitlement housing allowance program serving a large number of households or an inexpensive program serving a small number.

The minimum-standards housing allowance program tested in the Supply and Demand experiments resulted in modest increases in overall housing consumption as measured by the mean market rent of the units occupied and a substantial effect in terms of the fraction of eligible households meeting the program's minimum standards. Recipients in the Supply Experiment devoted 80 percent of their increased spending to goods other than housing. For a slight majority of recipients, the minimum housing standards were non-binding constraints. So the effect of the program on the consumption patterns of these households was an income effect alone. For many others, only modest improvements in their current housing were necessary to meet the standards. Indeed, the required improvements were so modest that many renters made them without involving their landlords.

Evidence from the Supply Experiment shows beyond a reasonable doubt that an entitlement housing allowance program similar to the one tested will have no significant effects on rents of units with specified characteristics even in the short run. Reasons for the program's small effect on rental housing prices are easy to find. Eligible families account for only a small fraction of the demand for housing services in a given housing market, and many of these families choose not to participate. So even a large increase in demand by participants will have a small effect on aggregate demand for housing services, and this small increase occurs gradually over time because not all families respond instantly to an offer of assistance. ${ }^{53}$ Furthermore, the Supply Experiment revealed that even over short periods suppliers are willing to make many changes in existing units in response to small changes in the profitability of housing with different characteristics.

\subsection{Reform Options}

The major options for reform of the system of housing subsidies to lowincome households are answers to the following questions. Should housing

53. The response to an offer of housing assistance with minimum housing standards is surely slower than the response to an offer of assistance for most other goods because many households must substantially renovate their current housing or move in order to receive assistance. Despite this drawback of tenant-based housing assistance of this form, it still gets households into satisfactory housing much faster than any form of new construction. The lag between authorization of funds and occupancy under all construction programs is much greater than the lag under this form of tenant-based assistance. 
assistance be an entitlement? Should housing subsidies be delivered to additional households by building new projects under some type of construction or substantial rehabilitation program or by giving them housing vouchers? Should we require households currently living in subsidized projects for which future federal expenditure is discretionary to live in these projects to receive a subsidy and should their owners be given a sufficient subsidy to induce them to continue to serve these households, or should these households be given housing vouchers? This section will consider each of these questions.

Unlike other major means-tested transfer programs, housing assistance is not an entitlement, despite its stated goal of "a decent home and suitable living environment for every American family" (Housing Act of 1949). No coherent justification for this feature of the system of housing subsidies has been offered. That is, no one has attempted to explain why we should offer assistance to some but not other households with the same characteristics.

It is difficult to reconcile these features of the Section 8 Existing Housing Program and all other low-income housing programs with plausible taxpayer preferences. In thinking about whether housing assistance should be an entitlement, it is helpful to think about how a nonrecipient who pays the taxes to support housing programs feels about dividing a fixed amount of assistance between two families that are identical in his or her eyes. At one extreme, we could give one of the families all of the money. At the other extreme, we could divide it equally between them. The former is inconsistent, and the latter consistent, with the usual assumptions about preferences, namely, that the amount that a person is willing to sacrifice for an additional unit of anything of value decreases as its quantity increases. To say that two potential recipients are the same in the eyes of a taxpayer is to say that the taxpayer is willing to sacrifice the same amount for the same change in the consumption pattern of either family. If all housing assistance goes to one potential recipient, the value to the taxpayer of the change in the consumption bundle resulting from the last dollar of housing assistance received by this recipient will be less than that resulting from the first dollar of housing assistance to the other recipient. Therefore, the taxpayer's well-being can be increased by reallocating housing assistance until both potential recipients receive the same assistance. Although each recipient would like to have more than half of the total, this obviously provides no guidance for policy.

The usual argument against making housing assistance an entitlement is that it would be too expensive. Those who make this argument seem to have in mind delivering housing assistance to all currently eligible households using the current mix of housing programs and the current rules for the tenant's contribution to rent. This would indeed increase the amount spent on housing assistance greatly, although this magnitude has not been estimated. However, we do not have to make more than 40 percent of the population eligible for housing assistance; we can reduce the fraction of 
housing assistance delivered through programs that are cost-ineffective, and we can reduce subsidies at every income level. Indeed, U.S. housing policy has been moving in this direction as a result of, first, a series of amendments of the 1937 Housing Act that required an increasing percentage of households served by tenant-based assistance to be the poorest of the currently eligible households; second, the introduction and rapid expansion of the cost-effective tenant-based Section 8 Program authorized by the 1974 Housing Act; and, third, the increase in the tenant contribution to rent mandated by the Housing and Community Development Amendments of 1981. Each of these reforms moved us in the direction of an entitlement program.

Furthermore, it is easy to develop an entitlement housing assistance program with any cost desired. For example, we could have an entitlement housing assistance program without spending any additional money by a simple change in the Section 8 Voucher Program, namely reducing the subsidy available to each eligible household by the same amount. This will effectively eliminate from the program all households currently eligible for subsidies smaller than this amount. These are the currently eligible households with the largest incomes. This would free up money to provide vouchers to poorer households who want to participate. The reduction in subsidies to those who continue to participate would free up money to provide vouchers to households with identical characteristics who had not previously been served. At current subsidy levels, many more people want to participate than can be served with the existing budget. As we reduced the subsidy at each income level, the number of households that are eligible for a subsidy and willing to participate would decline until we reached a point where all households who wanted to participate in the program were participating. So without any change in the program's budget, we could create an entitlement housing assistance program serving the poorest of the currently eligible households. If reductions in the subsidies received by current participants seem too draconian, we could phase in the new system by freezing subsidies at current levels and allowing inflation to erode real subsidy levels.

In discussions of housing policy, a common objection to this proposal is that no one would be able to find housing meeting the program's standards with the lower subsidies. Obviously, this objection is logically flawed. We start from a position where many more people want to participate than can be served with the existing budget. If we reduce subsidy levels slightly, it will still be the case that more people want to participate than can be served. If we decrease the subsidy levels so much that no one wants to participate, we have decreased them more than the proposed amounts.

A more sophisticated argument against the proposal is that the poorest households will be unable to participate in the proposed program. The simple proposal above calls for reducing the guarantee under the Voucher 
Program (called the Payment Standard). This is the subsidy received by a household with no income. If the Payment Standard is less than the rent required to occupy a unit meeting the program's minimum housing standards, then a household whose income and assistance from other sources is just sufficient to buy subsistence quantities of other goods would be unable to participate in the proposed Voucher Program. Previous studies (Olsen and Reeder 1983; Cutts and Olsen 2002) have shown that the Payment Standard exceeds the market rent of units just meeting the program's minimum housing standards in all of the many metropolitan areas and bedroom sizes studied. The median excess varied between 33 and 80 percent between 1975 and 1993. So a considerable reduction in the payment standard could occur almost everywhere without precluding participation by the poorest of the poor. However, the preceding proposal might lead to a particularly low participation rate by these households. This could be counteracted by a smaller reduction in the guarantee combined with a greater benefit reduction rate. For a given program budget, this would yield a higher participation rate by the poorest of the poor and a lower participation rate by other eligible households.

Another objection to the proposed program is that participants in the revised Section 8 Voucher Program would receive much smaller subsidies than the majority of identical households receiving project-based assistance, thereby introducing additional inequities into the system of housing subsidies. This objection could be overcome by increasing the tenant contribution under the programs of project-based assistance and using the savings from the reduced subsidies under these programs to increase the budget of the Voucher Program. If this were done, subsidies under the Voucher Program would not have to be reduced as much to make it an entitlement program, and hence the program's participation rate would be higher.

Should housing subsidies be delivered to additional households by building new projects under some type of construction or substantial rehabilitation program or by giving them housing vouchers?

The unanimity of the evidence on the cost-effectiveness of tenant-based vouchers compared with any form of project-based assistance studied is a strong argument for providing vouchers to all additional households receiving housing assistance, especially because the parameters of a voucher plan can be altered to change many of its other effects without affecting its cost-effectiveness or its total cost to taxpayers. For example, if we want to increase the participation rate of the poorest households at the expense of other eligible households, we can increase the program's guarantee (that is, the Payment Standard) and benefit reduction rate (that is, the tenant contribution as a fraction of adjusted income). Changes in the minimum housing standards, the payment standard, the benefit reduction rate, and the upper limit on housing expenditure will also lead to changes in consumption of housing and other goods. 
Two main objections have been raised to exclusive reliance on tenantbased assistance. ${ }^{54}$ Specifically, it has been argued that tenant-based assistance will not work in markets with the lowest vacancy rates and that new construction programs have an advantage compared with tenant-based assistance that offsets their cost-ineffectiveness: Namely, they promote neighborhood revitalization to a much greater extent.

Taken literally, the first argument is clearly incorrect in that Section 8 certificates and vouchers have been used continuously in all housing markets for more than two decades. It is true that some households who are offered vouchers do not find such housing within their housing authority's time limits. However, other eligible households use these vouchers. For many years, public housing authorities have over-issued vouchers and thereby achieved high usage rates despite low success rates. In recent years, they have had a reserve fund for this purpose, and current regulations call for penalties on authorities with usage rates below 95 percent. The national average usage rate is high (about 92 percent). So the overwhelming majority of certificates and vouchers are in use at each point in time. Local housing authorities rarely, if ever, return certificates and vouchers to HUD.

The real issue is not whether tenant-based vouchers can be used in all market conditions but whether it would be better to use new construction or substantial rehabilitation programs in some circumstances. In this regard, two questions seem especially important. Will construction programs get eligible households into satisfactory housing faster than tenantbased vouchers in some market conditions? Are construction programs more cost-effective than tenant-based vouchers under some circumstances? Although careful studies of these two questions have not been done, we can be very confident about the answer to the first questions.

Based on existing evidence, there can be little doubt that tenant-based vouchers get households into satisfactory housing much faster than any construction program even in the areas where the highest fraction of vouchers are returned unused. Two major studies of success rates under the tenant-based Section 8 program have been completed over the past fifteen years (Leger and Kennedy 1990a; Kennedy and Finkel 1994). These studies collected data on more than fifty local housing authorities selected at random. The lowest success rate observed was 33 percent for New York City in the mid-1980s. ${ }^{55}$ If a housing authority with this success rate issued only the vouchers available at each point in time and allowed recipients up

54. See Weicher (1990) for a more extended discussion of the voucher/production debate.

55. The success rate is the percentage of the households authorized to search for a unit who occupy a unit meeting the program's standards within the housing authority's time limit. The success rate in New York City in the mid-1980s was much lower than the second lowest (47 percent in Boston in the mid-1980s) and much lower than in New York City in 1993 (65 percent). An earlier study based on data from the late 1970s found lower success rates. However, at that time housing authorities were still figuring out how to administer this new program, so these success rates are of no relevance for predicting the effects of expanding the program today. 
to three months to find a unit meeting the program's standards, about 80 percent of the vouchers would be in use within a year. If they followed the current practice of authorizing more households to search for units than the number of vouchers available, almost all of the vouchers would be in use in much less than a year.

Based on data on a large stratified random sample of 800 projects built between 1975 and 1979, Schnare et al. (1982) found the mean time from application for project approval to completion of the project ranged from twenty-three months for Section 236 to fifty-three months for conventional public housing. Mean times ranged from twenty-six to thirty-one months for the variants of the Section 8 New Construction and Substantial Rehabilitation Program. Occupancy of the completed units required additional time. Although the authors did not report results separately for different markets, it seems reasonable to believe that these times were greater in the tightest housing markets because the demand for unsubsidized construction would be greatest in these locations. So if Congress were to simultaneously authorize an equal number of tenant-based vouchers and units under any construction program, it is clear that all of the vouchers would be in use long before the first newly built unit was occupied no matter what the condition of the local housing market at the time that the money is appropriated.

Although the cost-effectiveness studies discussed in section 6.4 are based on data for projects built in twenty-five cities at many different times and these studies are unanimous in finding that it costs significantly more than a dollar to provide a dollar's worth of housing under construction programs such as public housing, Section 236, and Section 8 New Construction, they do not report results that enable us to determine how the costeffectiveness of these programs vary with market conditions. Therefore, we cannot be certain that vouchers are more cost-effective than construction programs in all circumstances. Whether there are any market conditions under which construction programs are more cost-effective than vouchers is one of the most important unanswered questions in housing policy analysis.

The second major objection to the exclusive reliance on tenant-based assistance is that new construction promotes neighborhood revitalization to a much greater extent than tenant-based assistance. The evidence from EHAP is that even an entitlement housing voucher program will have modest effects on neighborhoods, and the small literature on the Section 8 Voucher Program confirms these findings for a similar nonentitlement program (Lowry 1983, 205-17; Galster, Tatian, and Smith 1999). These programs result in the upgrading of many existing dwellings, but this is concentrated on their interiors. It is plausible to believe that a new subsidized project built at low density in a neighborhood with the worst housing and poorest households would make that neighborhood a more attractive 
place to live for some years after its construction. The issue is not, however, whether some construction projects lead to neighborhood upgrading. The issues are the magnitude of neighborhood upgrading across all projects under a program over the life of these projects, who benefits from this upgrading, and the extent to which upgrading of one neighborhood leads to the deterioration of other neighborhoods.

Economic theory suggests that the primary beneficiaries of neighborhood upgrading will be the owners of nearby properties. Since the overwhelming majority of the poorest households are renters, it is plausible to believe that most of the housing surrounding housing projects located in the poorest neighborhoods is rental. Therefore, if a newly built subsidized project makes the neighborhood a more attractive place to live, the owners of this rental housing will charge higher rents and the value of their property will be greater. Since the occupants of this rental housing could have lived in a nicer neighborhood prior to the project by paying a higher rent, they are hurt by its construction. The poor will benefit from the neighborhood upgrading only to the extent that they own the property surrounding the project.

Housing programs involving new construction may primarily shift the location of the worst neighborhoods. With the passage of time, the initial residents will leave the neighborhood in response to the projects, and others who value a better neighborhood more highly will replace them. The desirability of the neighborhoods into which the original residents move will decline in response to their weaker demand for neighborhood amenities. The possibility of a shifting of the locations of the worst neighborhoods has not even been recognized in discussions of housing policy, let alone studied.

What has been studied is the extent to which projects under various housing programs affect neighborhood property values. The existing studies find small positive effects on average for some programs and small negative effects for others (Lee, Culhane, and Wachter 1999; Galster, Tatian, and Smith 1999). No study finds substantial positive effects on average for any program.

Should we require households currently living in subsidized projects for which future federal expenditure is discretionary to live in these projects to receive a subsidy and their owners to be given a sufficient subsidy to induce them to continue to serve these households, or should these households be given housing vouchers?

HUD devotes a substantial fraction of its budget for housing assistance to discretionary expenditures that provide additional subsidies to public housing authorities and the owners of privately owned subsidized projects in an attempt to insure that their projects provide satisfactory housing without charging rents that are regarded as excessive. For example, more than $\$ 6$ billion annually is spent on operating and modernization subsidies 
for public housing. Many units under all major construction programs that have been in existence for more than twenty years receive similar subsidies. Given the evidence on the cost-effectiveness of different methods of delivering housing assistance, an obvious policy reform is to replace these discretionary expenditures with tenant-based vouchers.

In the case of public housing, this reform would involve using the money currently devoted to operating and modernization subsidies to offer public housing tenants vouchers that can be used in private or public housing. ${ }^{56}$ At present, if tenants leave public housing, they lose their subsidies, so housing authorities have a captive audience. Under the proposed reform, housing authorities would be forced to compete with the private sector for tenants, albeit with the considerable advantage of having been given their projects.

To offset this large reduction in revenue and enable housing authorities to raise the money to continue to provide housing that meets program standards, they could be allowed to charge market rents for the units vacated after the implementation of the reform. Households with tenant-based vouchers would occupy many of these units. Other households eligible for housing assistance would occupy the rest. Public housing tenants who rejected vouchers would be able to remain in their apartments on the previous terms.

Housing authorities could raise additional money by taking advantage of the current regulation that allows them to sell projects. At present, they have little incentive to do it. Without guaranteed federal operating and modernization subsidies, many of the larger authorities may well decide to sell their worst projects. These are projects that will be largely abandoned by tenants with vouchers, and they are the most expensive to operate. If they are sold to the highest bidders, some of these buildings will undoubtedly be torn down and the land put to some better use.

In general, if vouchers are the most cost-effective method of providing housing assistance to additional households, they are also the most costeffective way to serve households currently living in housing projects. However, two other objections to vouchering out public housing warrant consideration.

One objection to this proposal is that it will force some tenants who prefer to stay in their current units to move. This objection applies equally to the current initiatives within the public housing program involving the demolition or major rehabilitation of projects. When these activities occur, displaced tenants are provided with tenant-based vouchers. It also applies equally to similar activities in the unsubsidized housing market. Legal prohibitions against this displacement are rare.

56. During its first term, the Clinton administration proposed this reform (HUD 1995). Robert Dole made a similar proposal during his presidential campaign. 
Another objection to the proposal is that it will reduce the number of affordable housing units. The meaning of this objection is not entirely clear. Since any dwelling is affordable with sufficient subsidy, vouchering out public housing does not change the number of affordable units unless it leads to a smaller housing stock. Even if vouchering out public housing led to the demolition of more public housing units than pursuing current policies, it does not follow that the total housing stock will be smaller on that account. When vacancy rates fall, private unsubsidized construction increases. Finally, this objection might refer to a reduction in the number of apartments reserved for occupancy by subsidized households. However, the advantages to assisted households or taxpayers of requiring subsidized households to live in particular units in order to receive a subsidy have not been explained. Among the disadvantages are the cost-ineffectiveness of project-based assistance and the severe limitation on the tenant's ability to adjust his or her housing in response to changes in circumstances such as job location.

Under all programs that provide substantial project-based assistance to private parties who build or rehabilitate housing for low-income households, these parties agreed to provide housing meeting certain standards to households with particular characteristics for a specified number of years. At the end of the use agreement, the government must decide whether to change the terms of the agreement, and the private parties must decide whether to participate on these terms. Since the government provides mortgage insurance for the overwhelming majority of these projects, it must also decide whether to provide additional subsidies to these projects when the private parties default on their loans or to sell these projects without subsidies. When use agreements are not renewed, current occupants are always provided with other housing assistance, usually tenant-based vouchers. ${ }^{57} \mathrm{Up}$ to this point, housing policy has leaned heavily in the direction of providing owners with a sufficient subsidy to induce them to continue to serve the low-income households in their projects.

Given the evidence on the cost-effectiveness of different methods of delivering housing assistance, an obvious policy reform is not to renew any use agreement and to provide the subsidized occupants of these projects with tenant-based vouchers. The issues involved in this decision are the same as those involved in the decision to voucher out public housing. However, it should be pointed out that for-profit sponsors will not agree to extend the use agreement unless this provides higher profits over the remaining life of the project than operating in the unsubsidized market. Since these subsidies are provided to selected private suppliers, the market mechanism

57. Indeed, they have normally been given the option of staying in their current apartment with the government paying the difference between the market rent of the unit and the standard tenant contribution or receiving the regular voucher that would be offered to any household with the same characteristics. 
does not insure that profits under the new use agreement will be driven down to market levels. If this does not happen, it will be more cost-effective to provide the occupants of these units with tenant-based vouchers.

\subsection{Summary and Conclusions}

The primary justification for housing subsidies to low-income households seems to be a desire on the part of many citizens to help these households combined with the view that many low-income households undervalue housing. To provide assistance consistent with this justification, an incredibly complicated system of housing programs has been developed, involving much larger indirect subsidies than is common for means-tested transfer programs. The total cost of this system exceeds the cost of other better-known parts of the welfare system. Only Medicaid is larger. The evidence on the major effects of housing programs is sparse or old or both. Based on this evidence, the effects of low-income housing programs can be summarized as follows.

In aggregate, all major housing programs increase housing consumption substantially, and almost all significantly increase consumption of other goods. The increase in housing consumption is especially marked for new construction programs in their early years. However, well before they reach the midpoint of their useful lives these projects have provided less desirable housing than the housing occupied by voucher recipients. All programs increase aggregate housing consumption more than would occur if each participant were given a cash grant equal to his or her housing subsidy.

The net effect of these changes in consumption patterns is that housing programs typically provide large benefits to their recipients. Although mean benefit is large compared with their mean income, it is small compared with the cost to taxpayers. The mean benefit is about 75 percent of the mean subsidy for construction programs and about 80 percent for vouchers. For vouchers the cost to taxpayers exceeds the subsidy by the modest administrative cost. For construction programs, the cost to taxpayers is much larger than the sum of the subsidy and administrative cost. The mean benefit of each program varies inversely with income and directly with family size, but the variance in real benefits among similar households is large under most programs.

For the entire system of housing subsidies, the participation rate among eligible households is far below 50 percent for each combination of income and family size. For each family size, the participation rate first rises and then falls as income increases. The poorest households of each size have very low participation rates. Within each income class, participation rates are highest for one-person households, reflecting the strong preference received by the elderly in housing programs.

Evidence on the effect of housing programs on the characteristics of the 
neighborhoods in which recipients live is particularly meager. It suggests that public housing tenants live in noticeably worse neighborhoods than in the absence of the program and that the program contributes to racial segregation in housing. Section 8 New Construction/Substantial Rehabilitation and Section 8 certificates and vouchers appear to have modest effects in the opposite direction. The existing studies find small positive effects on neighboring property values on average for some programs and small negative effects for others. No study finds substantial positive effects on average for any program.

Housing programs appear to have small work disincentive effects. They also have miniscule effects on the prices of unsubsidized units that are not located near subsidized units.

The most important finding of the empirical literature from the viewpoint of housing policy is that tenant-based vouchers and certificates provide equally good housing at a much lower cost than any type of projectbased assistance that has been studied. This finding implies that a shift of all discretionary resources from programs of project-based assistance to tenant-based vouchers would enable us to provide several million additional households with adequate housing at an affordable rent without any increase in government expenditure.

The major issues in housing policy for low-income households are (a) whether housing assistance should be an entitlement, (b) whether housing subsidies should be delivered to additional households by building new projects under some type of construction or substantial rehabilitation program or by giving them housing vouchers, and (c) whether we should require households currently living in subsidized projects for which future federal expenditure is discretionary to live in these projects to receive a subsidy and should give their owners a sufficient subsidy to induce them to continue to serve these households, or give these households housing vouchers. The available empirical evidence has much to contribute to the policy debate over these important questions. However, the magnitude of the public expenditures involved argues for producing better information on which to base these decisions. This evidence should be based on recent data on the full range of major housing programs for low-income households.

\section{References}

Barnett, C. L., and Lowry, Ira S. 1979. How housing allowances affect housing prices. Santa Monica, Calif.: The RAND Corporation, October.

Bradbury, Katherine, and Anthony Downs. 1981. Do housing allowances work? Washington, D.C.: Brookings Institution. 
Buron, Larry, Sandra Nolden, Kathleen Heintz, and Julie Stewart. 2000. Assessment of the economic and social characteristics of LIHTC residents and neighborhoods. Final report. Cambridge, Mass.: Abt Associates, August.

Carliner, Michael S. 1998. Development of federal homeownership "policy." Housing Policy Debate 9:299-321.

Clemmer, Richard B. 1984. Measuring welfare effects of in-kind transfers. Journal of Urban Economics 15:46-65.

Crews, Amy D. 1995. Self-selection, administrative selection, and aggregation bias in the estimation of the effects of in-kind transfers. Ph.D. diss., University of Virginia.

Cummings, Jean L., and Denise DiPasquale. 1999. The Low-Income Housing Tax Credit: An analysis of the first ten years. Housing Policy Debate 10:251-307.

Currie, Janet, and Aaron Yelowitz. 2000. Are public housing projects good for kids? Journal of Public Economics 75:99-124.

Cutts, Amy Crews, and Edgar O. Olsen. 2002. Are Section 8 housing subsidies too high? Journal of Housing Economics 11:214-43.

De Leeuw, Frank, and Raymond J. Struyk. 1975. The web of urban housing. Washington, D.C.: Urban Institute.

Early, Dirk W. 1998. The role of subsidized housing in reducing homelessness: An empirical investigation using micro-data. Journal of Policy Analysis and Management 17:687-96.

Friedman, Joseph, and Daniel H. Weinberg. 1982. The economics of housing vouchers. New York: Academic Press.

1983. The great housing experiment. Beverly Hills, Calif.: Sage Press.

Galster, George C., Peter Tatian, and Robin Smith. 1999. The impact of neighbors who use Section 8 certificates on property value. Housing Policy Debate 10:879917.

Hammond, Claire H. 1987. The benefits of subsidized housing programs: An intertemporal approach. Cambridge: Cambridge University Press.

Kain, John F. 1981. A universal housing allowance program. In Do housing allowances work? ed. Katherine Bradbury and Anthony Downs, 339-65. Washington, D.C.: Brookings Institution.

Katz, Lawrence F., Jeffrey R. Kling, and Jeffrey B. Liebman. 2001. Moving to opportunity in Boston: Early results of a randomized mobility experiment. Quarterly Journal of Economics 116 (May): 607-54.

Keane, Michael, and Robert Moffitt. 1998. A structural model of multiple welfare program participation and labor supply. International Economic Review 39 (August): 553-89.

Kennedy, Stephen D. 1980. Housing allowance demand experiment: Final report. Cambridge, Mass.: Abt Associates, June.

Kennedy, Stephen D., and Meryl Finkel. 1994. Section 8 rental voucher and rental certificate utilization study. Cambridge, Mass.: Abt Associates.

Kraft, John and Edgar O. Olsen. 1977. The distribution of benefits from public housing. In The distribution of economic well-being, ed. F. T. Juster, 51-65. New York: National Bureau of Economic Research.

Lee, Chang-Moo, Dennis P. Culhane, and Susan M. Wachter. 1999. The differential impacts of federally assisted housing programs on nearby property values: A Philadelphia case study. Housing Policy Debate 10:75-93.

Leger, Mireille L., and Stephen D. Kennedy. 1990a. Final comprehensive report of the Freestanding Housing Voucher Demonstration. Vols. 1 and 2. Cambridge, Mass.: Abt Associates, May.

1990b. Recipient housing in the housing voucher and certificate programs. Cambridge, Mass.: Abt Associates, May. 
Lowry, Ira S., ed. 1983. Experimenting with housing allowances: The final report of the Housing Assistance Supply Experiment. Cambridge, Mass.: Oelgeschlager, Gunn, \& Hain.

Ludwig, Jens, Greg J. Duncan, and Joshua C. Pinkston. 2001. Urban poverty and juvenile crime: Evidence from a randomized housing-mobility experiment. Quarterly Journal of Economics 116 (May): 655-79.

Ludwig, Jens, Helen F. Ladd, and Greg J. Duncan. 2001. Urban poverty and educational outcomes. In Brookings-Wharton papers on urban affairs, ed. William G. Gale and Janet Rothenberg. Washington, D.C.: Brookings Institution.

Mayo, Stephen K. 1986. Sources of inefficiency in subsidized housing programs: A comparison of U.S. and German experience. Journal of Urban Economics 20 (September): 229-49.

Mayo, Stephen K., Shirley Mansfield, David Warner, and Richard Zwetchkenbaum. 1980a. Housing allowances and other rental assistance programs-A comparison based on the Housing Allowance Demand Experiment, part 1: Participation, housing consumption, location, and satisfaction. Cambridge, Mass.: Abt Associates.

. 1980b. Housing allowances and other rental assistance programs-A comparison based on the Housing Allowance Demand Experiment, part 2: Costs and efficiency. Cambridge, Mass.: Abt Associates.

Mikesell, James J., Linda M. Ghelfi, Priscilla Salant, George Wallace, and Leslie A. Whitener. 1999. Meeting the housing needs of rural residents: Results of the 1998 survey of USDA's Single Family Direct Loan Program. Rural Development Research Report no. 91. Washington, D.C.: United States Department of Agriculture, Economic Research Service, December.

Mills, Edwin S., and Arthur Sullivan. 1981. Market effects. In Do housing allowances work? ed. Katherine Bradbury and Anthony Downs, 247-76. Washington, D.C.: Brookings Institution.

Murray, Michael. 1975. The distribution of tenant benefits in public housing. Econometrica 43 (July): 771-88.

1980. A reinterpretation of the traditional income-leisure model, with application to in-kind subsidy programs. Journal of Public Economics 14:69-81.

. 1983. Subsidized and unsubsidized housing starts: 1961-1977. Review of Economics and Statistics 65 (November): 590-97.

1999. Subsidized and unsubsidized housing stocks 1935 to 1987: Crowding out and cointegration. Journal of Real Estate Economics and Finance 18:10724.

Newman, Sandra J., and Joseph M. Harkness. 2002. The long-term effects of public housing on self-sufficiency. Journal of Policy Analysis and Management 21 (Winter): $21-43$.

Newman, Sandra J., and Ann B. Schnare. 1997. “. . . And a suitable living environment": The failure of housing programs to deliver on neighborhood quality. Housing Policy Debate 8:703-41.

Nolden, Sandra, Jessica Bonjorni, Carissa Climaco, Naomi Michlin, and Karen Rich. 2002. Updating the Low Income Housing Tax Credit (LIHTC) Database: Projects Placed in Service Through 1999. Final report. Contract C-OPC-21293. Cambridge, Mass.: Abt Associates.

Olsen, Edgar O. 1981. The simple analytics of the externality argument for redistribution. In Economic perspectives: An annual survey of economics, ed. M. B. Ballabon, 155-73. Vol. 2. New York: Harwood Academic Publishers.

1983. The implications of the Experimental Housing Allowance Program

for housing policy. In The great housing experiments, ed. Joseph Friedman and Daniel Weinberg. Beverly Hills, Calif.: Sage Publications. 
2000. The cost-effectiveness of alternative methods of delivering housing subsidies. Working Paper no. 351. University of Virginia, Thomas Jefferson Center for Political Economy, December.

Olsen, Edgar O., and David M. Barton. 1983. The Benefits and Costs of Public Housing in New York City." Journal of Public Economics 20 (April): 299-332.

Olsen, Edgar O., and William Reeder. 1983. Misdirected rental subsidies. Journal of Policy Analysis and Management 2 (Summer): 614-20.

Painter, Gary. 1997. Does variation in public housing waiting lists induce intraurban mobility? Journal of Housing Economics 6:248-76.

Reeder, William J. 1985. The benefits and costs of the Section 8 Existing housing program. Journal of Public Economics 26 (April): 349-77.

Reid, William J. 1989. A benefit-cost analysis of Section 23 leased public housing. Ph.D. diss., University of Virginia.

Rydell, C. Peter, Kevin Neels, and C. Lance Barnett. 1982. Price effects of a housing allowance program. Report no. R-2720. Santa Monica, Calif.: RAND Corporation.

Schnare, Ann, Carla Pedone, William Moss, and Kathleen Heintz. 1982. The costs of HUD multifamily housing programs: A comparison of the development, financing, and life cycle costs of Section 8, public housing, and other major HUD programs. Vols. 1 and 2. Cambridge, Mass.: Urban Systems Research and Engineering.

Schone, Barbara Steinberg. 1992. Do means tested transfers reduce labor supply? Economics Letters 40:353-58.

1994. Estimating the distribution of taste parameters of households facing complex budget spaces: The effects of in-kind transfers. Agency for Health Care Policy and Research. Unpublished manuscript.

Schwab, Robert M. 1985. The benefits of in-kind government programs. Journal of Public Economics 27 (July): 195-210.

Stegman, Michael A. 1991. The excessive costs of creative finance: Growing inefficiencies in the production of low-income housing. Housing Policy Debate 2:35773.

Struyk, Raymond J., and Marc Bendick, eds. 1981. Housing vouchers for the poor: Lessons from a national experiment. Washington, D.C.: The Urban Institute Press.

Susin, Scott. 2002. Rent vouchers and the price of low-income housing. Journal of Public Economics 83 (January): 109-52.

U.S. Department of Commerce, Bureau of the Census. 1991. American housing survey for the United States in 1989. Current Housing Reports. Series H150/89. Washington, D.C.: Government Printing Office.

U.S. Department of Housing and Urban Development (HUD). 1974. Housing in the seventies. Washington, D.C.: Government Printing Office.

- 1980. Experimental Housing Allowance Program: The 1980 report. Washington, D.C.: Government Printing Office, February.

. 1992. Characteristics of HUD-assisted renters and their units in 1989. Washington, D.C.: Government Printing Office.

-1995. HUD reinvention: From blueprint to action. Washington, D.C.: Government Printing Office, March.

1997. Characteristics of HUD-assisted renters and their units in 1993. Washington, D.C.: Government Printing Office, May.

— 2000. Rental housing assistance — the worsening crisis: A report to Congress on worst case housing needs. Washington, D.C.: Government Printing Office.

U.S. General Accounting Office (GAO). 1997. Tax credits: Opportunities to improve 
oversight of the low-income housing programs. GAO/GGD/RCED-97-55. Washington, D.C.: U.S. GAO.

. 2001. Federal housing programs: What they cost and what they provide. GAO-01-901R. Washington, D.C.: U.S. GAO.

.2002. Federal housing assistance: Comparing the characteristics and costs of housing programs. GAO-02-76. Washington, D.C.: U.S. GAO.

U.S. House of Representatives, Committee on Ways and Means. 1998. 1998 green book: Background material and data on programs within the jurisdiction of the Committee on Ways and Means. Washington, D.C.: Government Printing Office.

Wallace, James E. 1995. Financing affordable housing in the United States. Housing Policy Debate 6:785-814.

Wallace, James E., Susan Philipson Bloom, William L. Holshouser, Shirley Mansfield, and Daniel H. Weinberg. 1981. Participation and benefits in the urban Section 8 Program: New construction and existing housing. Vols. 1 and 2. Cambridge, Mass.: Abt Associates.

Weicher, John C. 1979. Urban housing policy. In Current issues in urban economics, ed. P. Miezkowski and M. Straszheim, 469-508. Baltimore, Md.: John Hopkins University Press.

1990. The voucher/production debate. In Building foundations: Housing and federal policy, ed. Denise DiPasquale and Langley C. Keyes, 263-92. Philadelphia: University of Pennsylvania Press.

Weinberg, Daniel H. 1982. Housing benefits from the Section 8 Program. Evaluation Review 6 (February): 5-24. 
